Portland State University

PDXScholar

Winter 3-12-2019

\title{
Concerted Cultivation, Academic Achievement, and the Mediating Role of Non-Cognitive Factors
}

Bryant Carlson

Portland State University

Follow this and additional works at: https://pdxscholar.library.pdx.edu/open_access_etds

Part of the Educational Sociology Commons

Let us know how access to this document benefits you.

Recommended Citation

Carlson, Bryant, "Concerted Cultivation, Academic Achievement, and the Mediating Role of Non-Cognitive Factors" (2019). Dissertations and Theses. Paper 4807.

https://doi.org/10.15760/etd.6691

This Dissertation is brought to you for free and open access. It has been accepted for inclusion in Dissertations and Theses by an authorized administrator of PDXScholar. Please contact us if we can make this document more accessible: pdxscholar@pdx.edu. 
Concerted Cultivation, Academic Achievement, and the Mediating Role of Non-

Cognitive Factors

\author{
by \\ Bryant Carlson
}

A dissertation submitted in partial fulfillment of the requirements for the degree of

\author{
Doctor of Philosophy \\ in \\ Sociology
}

\title{
Dissertation Committee: \\ Bob Liebman, Chair \\ Ramin Farahmandpur \\ Dara Shifrer \\ Lindsey Wilkinson
}

Portland State University

2019 
(C) 2018 Bryant Carlson 


\begin{abstract}
Previous research has focused on the role concerted cultivation has played as a pathway to academic achievement and cognitive skill acquisition, but there has been little to no attention given to the potential role concerted cultivation plays as a pathway to noncognitive factors that shape academic achievement in school (Bowles and Gintis 1976/2011; Heckman and Kautz 2012). There is substantial evidence that non-cognitive factors significantly determine educational and economic mobility (Bowles and Gintis 1976/2011; Heckman and Kautz 2012), but we know relatively little about the specific role that parenting style, and concerted cultivation in particular, plays in shaping noncognitive factors. The work of Bourdieu (1977) provides a rationale to hypothesize that the pathway connecting concerted cultivation to academic achievement is mediated by non-cognitive factors.

Overall, the results support the central hypothesis of the study positing that noncognitive factors mediates the relationship between concerted cultivation and academic achievement. Each of the non-cognitive variables assessed, positive behavior, behavior problems, and mastery, significantly mediate the effect concerted cultivation domains have on academic achievement. Specifically, positive behavior significantly mediates the relationship between parental involvement and both reading score and high school GPA; behavior problems significantly mediates the relationship between parental involvement and reading score and language patterns and reading score, and parental involvement and high school GPA and language patterns and high school GPA; and mastery significantly mediates the relationship between parental involvement and reading score.
\end{abstract}




\section{Dedication}

A central premise of this dissertation is that features of our social background are highly determinative toward mobility or immobility in academic and economic institutions. We neither begin nor end our academic journey on a level playing field, as we are typically placed onto relatively stable trajectories early in life based on the resources and people available to us well before we begin school.

In other words, moms are important. Accordingly, the analytical model in this dissertation begins with a variable related to the impact of moms. Should you make it to the results section, you will read about the multiple pathways through which moms positively scaffolded the development of the children in the sample and strategically intervened on their behalf in institutionally informed ways.

The use of an independent variable related to moms was somewhat ironic, because of all people I did not need a PhD to know how profoundly a mom can shape and even determine positive outcomes and the type of readiness and sense of self one needs to pursue opportunities that at times appear beyond reach. Any achievement of mine, and this one in particular, is essentially an outcome of the resources, love, and support she has always provided.

There were a few unexpected and highly impactful losses during the pursuit of this degree, and my mom helped me through those to this place in ways that could not possibly be captured with words or a regression coefficient. In countless ways my mom made the completion of this $\mathrm{PhD}$ possible, and with deep love and gratitude I dedicate it to her. 


\section{Table of Contents}

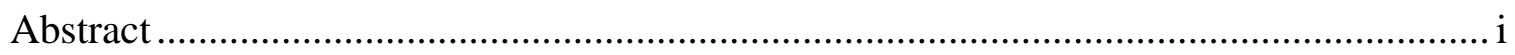

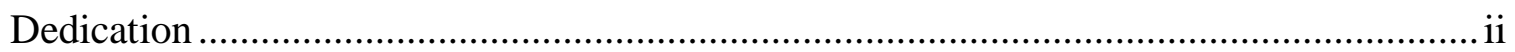

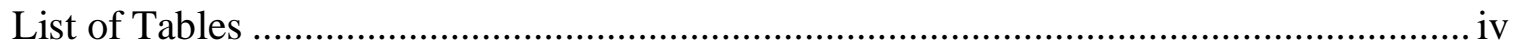

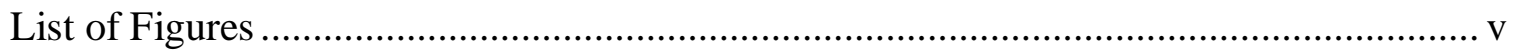

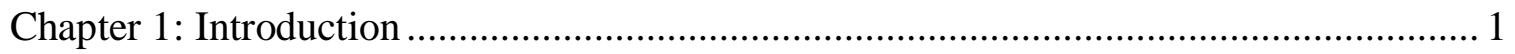

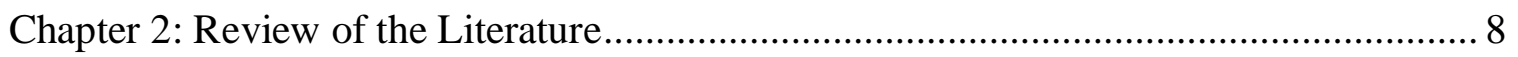

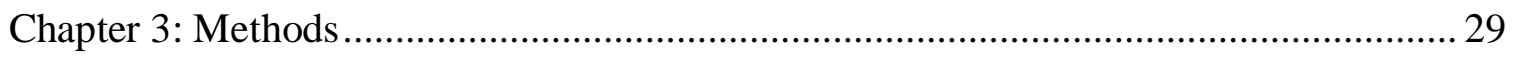

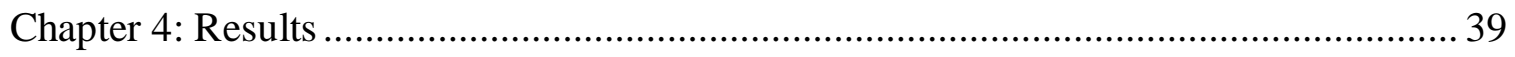

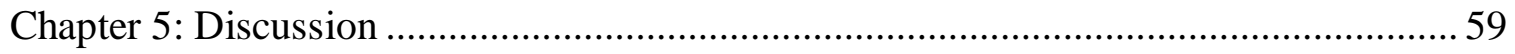

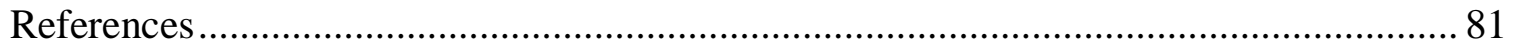




\section{List of Tables}

Table 1: Means, Standard Deviations, and Correlations among Main Variables and

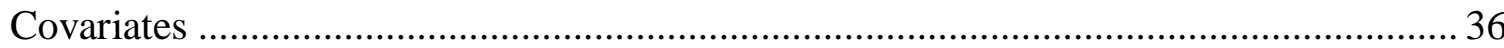

Table 2: The Effect of Mother's Education and Educational Expectations on Concerted

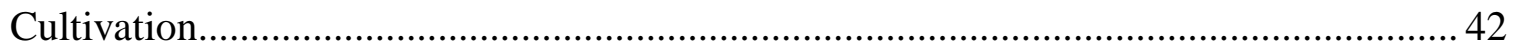

Table 3: The Effect of Concerted Cultivation on Non-Cognitive Factors ....................... 45

Table 4: The Effect of Non-Cognitive Factors on Academic Achievement.................... 49

Table 5: Mediating Effects of Positive Behavior........................................................ 53

Table 6: Mediating Effects of Behavior Problems ......................................................55

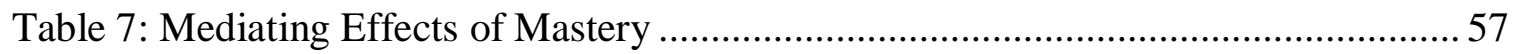




\section{List of Figures}

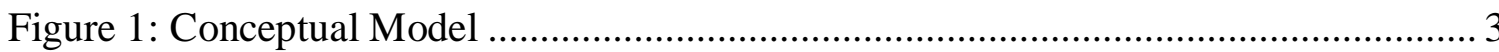

Figure 2: Model of the Pathways through which Non-Cognitive Factors Mediate the Influence of Concerted Cultivation on Academic Achievement ...................................... 40

Figure 3: Research Question 1: Mother's Education, Educational Expectations and

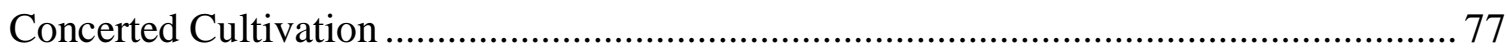

Figure 4: Research Question 2: Concerted Cultivation and Non-Cognitive Factors ........ 78

Figure 5: Research Question 3: Non-Cognitive Factors and Academic Achievement..... 79

Figure 6: Research Question 4: The Mediating Influence of Non-Cognitive Factors ...... 80 


\section{Chapter 1: Introduction}

Previous research has focused on the role concerted cultivation has played as a pathway to academic achievement and cognitive skill acquisition, but there has been relatively little attention given to the potential role concerted cultivation plays as a pathway to non-cognitive factors that shape academic achievement in school (Bowles and Gintis 1976; Heckman and Kautz 2012; Bodivski and Farkas 2008), despite substantial evidence that non-cognitive factors such as social behaviors significantly determine educational and economic mobility (Bowles and Gintis 1976; Heckman and Kautz 2012). Consequently, we know relatively little about the specific role that parenting style, and concerted cultivation in particular, plays in shaping non-cognitive factors. Although there are growing literatures on the determinative effects of specific parenting styles on academic achievement and on non-cognitive factors on academic achievement, there have been few attempts to merge these previously independent but related literatures. The work of Bourdieu (1977) provides a rationale to hypothesize that the pathway connecting concerted cultivation to academic achievement is mediated by non-cognitive factors.

The central purpose of this study is to empirically examine these relationships addressing the following research questions: The degree to which mother's education and educational expectations are associated with concerted cultivation; the degree to which parenting, specifically concerted cultivation, is associated with non-cognitive factors in school; the degree to which non-cognitive factors are associated with academic achievement; and the degree to which non-cognitive factors mediate the relationship between concerted cultivation and academic achievement. Using longitudinal data from the Panel Study of Income Dynamics (PSID) $(N=791)$ and its supplements, the Child 
Development Study (CDS-I and II from 1997 and 2002) and Transition to Adulthood (TA-2009 and TA-2011) Study, this study assesses composite quantitative measures of concerted cultivation (developed by Carolan and Wasserman [2015] using the same PSID data) and non-cognitive factors. Figure 1 provides a conceptual model of the research. 


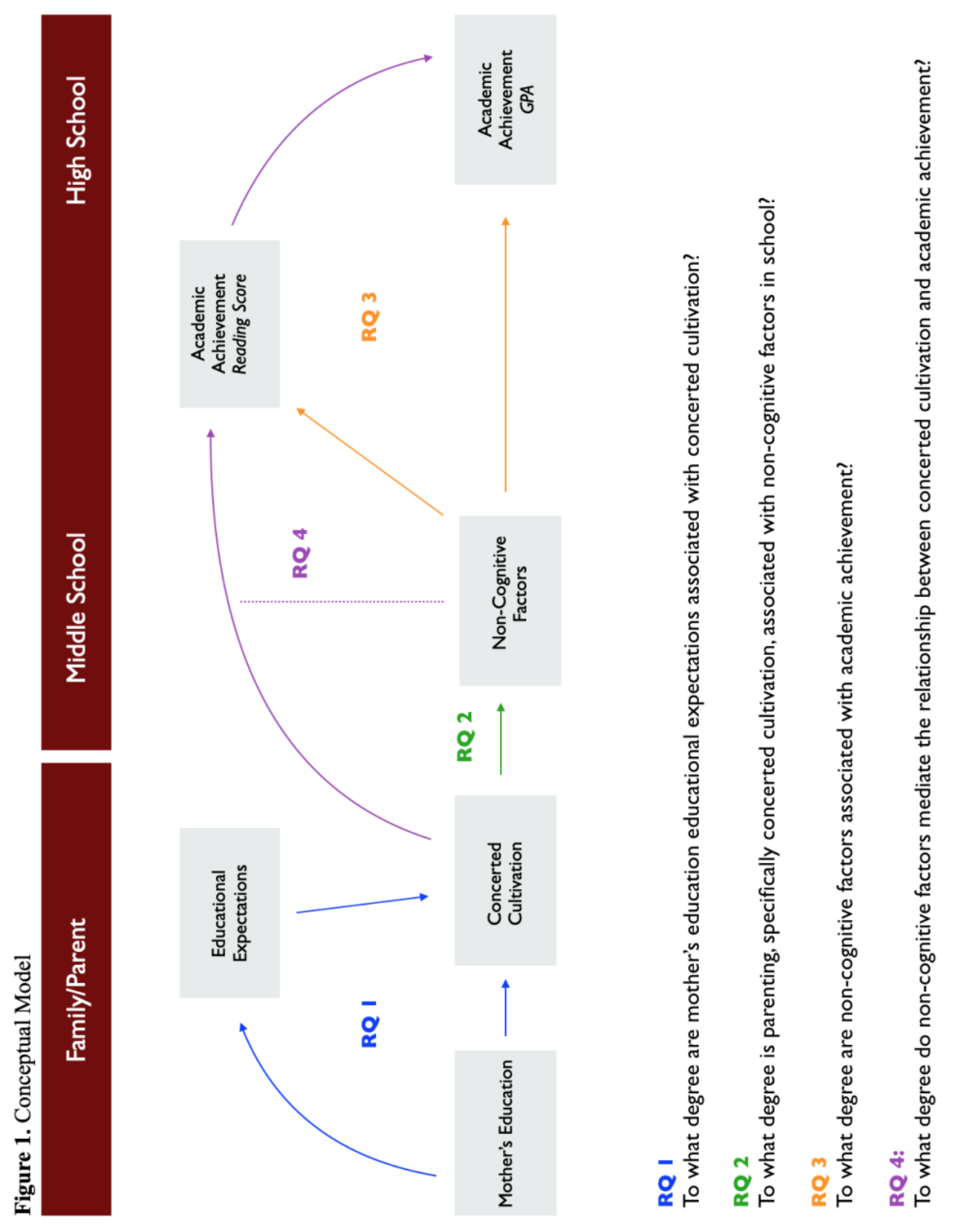


Academic performance is a multi-faceted outcome that is the result of intraindividual, interpersonal, and social contextual factors interacting to shape student functioning and the wider social climate within which students learn and are evaluated. Along with the need to deepen "cognitive" skills like learning content domains and increasingly expanding their fund of knowledge, students are also expected to demonstrate non-cognitive skills such as behaviors and attitudes that facilitate achievement in schools. The acquisition of these non-cognitive skills is significantly shaped by early socialization practices. Social conditions in a household early in life figure significantly on outcomes throughout the lifespan. Indeed, the years of life preceding school are characterized as a particularly sensitive period: "The ability gaps between individuals and across socioeconomic groups open up at early ages, for both cognitive and non-cognitive skills" (Heckman 2008:308). Children from lower-income households begin school behind on every metric typically used to evaluate school readiness (Duncan and Magnuson 2011). These disparities appear to remain relatively stable into adulthood and beyond (Alexander et al. 2014).

Research across the social sciences on the intergenerational transmission of educational advantage suggests that social and cultural capital factors play a central role. Decades of research confirm Bourdieu's (1977) theory that social hierarchies invariably become academic hierarchies within educational systems, such that the middle and upperclass behaviors, knowledge, and dispositions (i.e. habitus) of teachers are preferred and the corresponding performance by students is rewarded (Lareau 2015).

Over the past 20 years researchers have sought to identify distinct parenting styles that appear to function as mechanisms through which cultural capital is transferred from 
parents to children. This research largely focuses on the assumptions and behaviors that underlie the interactive patterns between parents and children (Lareau 2003; Bodovski and Farkas 2008). Lareau (2003) describes how social class-based cultural patterns, habits, and skills are created and reinforced by different parenting approaches, suggesting that these alternative approaches to parenting explain in part how social class is reproduced in schools. According to Lareau, middle and upper-class parents practice a "concerted cultivation" style, characterized by deliberately nurturing in their children the skills and habits viewed as constitutive of success in schools and beyond. Children in these families spend considerable time in structured activities administered by adults (e.g., music, sports, clubs). Lareau observed working-class parents using a less hands-on approach, which she described as "natural growth," characterized by a view of parenting in which parents provide the essential elements for development (e.g., food, security, love), but in other areas allow children to develop on their own.

Lareau's research suggests that a concerted cultivation parenting approach scaffolds the acquisition of skills and habits deemed constitutive of success in academic systems. These skills and habits, including mastery, persistence, self-control, and social skills, are often generally referred to as "non-cognitive factors" in the empirical literature, and sometimes as "soft skills" (Myint 2016; Heckman 2008). Research in education and various social science disciplines has found that non-cognitive factors play a crucial role in academic achievement (Stankov et al. 2014; Farrington et al. 2012). Many studies have found that non-cognitive factors have a direct positive relationship to both academic performance and educational achievement (Liu 2016; Farrington et al. 2012). Recent research evaluating the impact of interventions designed to modify student psychosocial 
beliefs, including interventions facilitating a sense of belonging and restructuring student beliefs about personal intelligence, have reported significant effects on academic achievement that have endured over time (Blackwell et al. 2007; Oyserman et al. 2002).

To date, researchers have yet to examine the degree to which these non-cognitive factors so critical to academic achievement and educational success might be specifically cultivated by parents. This research suggests that a natural place to begin is Lareau's class-based concerted cultivation parenting approach. Lareau (2003) reports parenting style differences by social class across four areas: perceptions of parental responsibility, the use of language in the home, organization of extracurricular activities, and parental readiness to intervene in school on behalf of their children. The concerted cultivation approach, in each of these four areas, appears to have quantitative advantages for middleclass children: more activities than their working-class peers, more frequent and nuanced verbal interactions, and a higher number of parents prepared to successfully intervene at school (e.g., enrolled in special programs). Concerted cultivation practices appear to correspond with the standards and cultural expectations of educational institutions and the gatekeepers for mobility located within them (Lareau 2003; Bodivski and Farkas 2008; Heckman and Kautz 2012; Heckman 2008), conferring significant advantages to middle-class children. Several previous studies seeking to quantitatively examine the impact of concerted cultivation on children's academic achievement have reported positive relationships. Bodovski and Farkas (2008) report significant, though relatively moderate, relationships between concerted cultivation and test scores and teacher judgements of student literacy and language performance. Roksa and Potter (2011) found relationships between social background and academic achievement that was partially 
explained by concerted cultivation and other family resources. In a panel study with 10,350 students, Carolan (2015) reports a significant relationship between social class, concerted cultivation, and academic achievement, measured by math scores in grades 9 and 11. However, unlike Bodovski and Farkas (2008), Roksa and Potter (2011), and Carolan (2015), Carolan and Wasserman (2015) do not report significant associations between concerted cultivation and academic achievement, though they found a significant relationship between parental educational expectations and academic achievement. This study builds on these previous efforts to quantitatively assess Lareau's concerted cultivation construct through an analysis that adds the mediating role of noncognitive factors to the model.

Using longitudinal data from the Panel Study of Income Dynamics (PSID) and its supplements, the Child Development Study (CDS-I and II from 1997 and 2002) and Transition to Adulthood (TA-2009 and TA-2011) Study to create a sample $(N=791)$, this study assesses composite quantitative measures of concerted cultivation (developed by Carolan and Wasserman [2015] using the same PSID data) and non-cognitive factors to address the following research questions:

- To what degree are mother's education and educational expectations associated with concerted cultivation?

- To what degree is parenting, specifically concerted cultivation, associated with noncognitive factors in school?

- To what degree are non-cognitive factors associated with academic achievement?

- To what degree do non-cognitive factors mediate the relationship between concerted cultivation and academic achievement? 


\section{Chapter 2: Review of the Literature}

\section{Cultural Capital and Social Reproduction}

Concern over the role of the U.S. education system in the reproduction of social class formally began as a product of the political and intellectual ferment of the $1960 \mathrm{~s}$ (Collins 2009:34). The Coleman Report (1966), which was expected to implicate the role of schools in inequality, instead found that family social class status was the greatest determinant of children's academic achievement and life chances (Hill 2016; Haertel 2013; Anyon 2011; Gamoran and Long 2006). That finding holds fifty years later (Duncan and Murnane 2011). While billions have been spent on school-based programs to equalize educational outcomes, children's futures seem to remain inextricably tied to family circumstances and resources, and parenting style.

Bourdieu's perspective on the reproduction of social class provides a subtle framework relating forms of symbolic value (e.g., social, cultural, economic capital) to economic and political contexts, with attention given to forms of "pedagogic discourse" that result in systemic and patterned miscommunication in classrooms and beyond (Collins 2009; Bourdieu and Passeron 1977). For Bourdieu, social class-based differences in material and cultural capital are the primary mechanisms through which educational inequalities are reproduced: "The educational system demands of everyone alike that they have what it does not give...and can only be produced by family upbringing when it transmits the dominant culture', (Bourdieu 1977:494).

The reproduction of social class was explained by Bourdieu using a game as a metaphor for the highly stratified social contexts of life. For Bourdieu, cultural capital refers to the resources available to a person, whether social, cultural, or economic; habitus refers to a 
person's dispositional characteristics that emerge from their standing in the game; and field refers to the broader social world within which an individual game is played. Accordingly, inequalities in cultural capital, and the subsequent differences in habitus, serve to shape academic outcomes, thereby reproducing social class.

Throughout his writing Bourdieu appears to have been sensitive to issues of power, particularly the ways in which powerful groups dominate resources. Lareau (2003), who characterizes her work on concerted cultivation as an empirical application of Bourdieu's theory, notes that Bourdieu's perspective "is interested in the power of individuals to define what constitutes a highly valued activity, but also to the reasons why particular social practices are valued more highly than others" (361). At the core of the social structure, Bourdieu observes a pattern of domination and inequality. His perspective on the reproduction of social class posits that a lack of familiarity with the dominant culture (i.e., lack of cultural capital) leads to deficiencies of the desired dispositional characteristics that emerge from such familiarity (i.e., habitus), resulting in blocks to upward mobility for those from lower social class backgrounds beginning as youth in schools and, subsequently, to their lives as adults (Gaddis 2013).

Bourdieu contends that middle and upper-class homes instill cultural capital to their offspring, enabling their children to succeed in K-12 schools and obtain higher academic credentials than their poor and working-class peers. This enables middle and upper-class individuals to maintain their social class position, thereby legitimizing the dominant positions that middle and upper-class individuals routinely go on to maintain. Although some poor and working-class students will succeed in the educational system, these exceptions do not challenge the prevailing system, but, according to Bourdieu's 
perspective, instead strengthen it by contributing to the façade of meritocracy (Sullivan 2001).

A considerable amount of research validating the role cultural capital plays in the reproduction of social class has emerged in recent decades. Lareau (2015) combined qualitative longitudinal data from her Unequal Childhoods study and interview data from a study of upwardly mobile adults to investigate the role cultural knowledge plays when young adults from different social class backgrounds navigate higher education institutions. Employing Bourdieu's concept of cultural capital, Lareau (2015) theorized that different socialization practices by social class would have shaped the amount and forms of resources available to the young adults. These forms of cultural capital, "skills individuals inherit that can be translated into different forms of value as people move through different institutions" (4), are critical to upward social mobility. Lareau's (2015) analysis found social class differences in three forms of cultural knowledge essential to the reproduction of social class, including institutional knowledge related to mobility, preferred dispositions, and barriers. Specifically, middle-class young adults had better knowledge about how institutions worked (e.g., requisite grades for medical school admission) than the working-class young adults. Moreover, whereas middle-class youth were largely more assertive about seeking help, working-class young adults reported feeling shy and uncomfortable soliciting help. Additionally, when confronting an institutional barrier, middle-class young adults called upon prior experience and knowledge to successfully navigate through the barrier, while working-class young adults were less likely to successfully navigate their barriers. 
Seeking to expand the traditional boundaries associated with Bourdieu's notion of cultural capital, Lareau contends that the forms of cultural knowledge assessed in her study (e.g., formal and informal rules, strategies for accessing assistance and navigating barriers) are qualitatively distinct from cultural capital forms like academic knowledge and "soft-skill" dispositional characteristics, though just as determinative for upward social mobility.

The recent work of Gaddis (2013) also demonstrates the usefulness of Bourdieu's concept of cultural capital. Gaddis used a longitudinal dataset to examine the effects of cultural capital on educational achievement, and the mediating effects of habitus. Gaddis reports that cultural capital had positive effects on GPA that are mediated through habitus. This finding is not necessarily surprising given that research indicates that disadvantaged youth are exposed to stereotypes implying that IQ is fixed and that they are less intelligent (Steele and Aronson 1995). According to Gaddis (2013), the exposure of poor and working-class students to cultural capital would presumably increase their knowledge of both the educational system and the contextual nature of IQ, particularly if they were exposed to features of high-status culture. Such exposure may in turn demonstrate the link between the acquisition of education-related capital and academic performance, reinforce the notion that non-classroom learning contributes to the malleability of IQ, and potentially increase interest and motivation as high-status habits like reading novels or visiting museums may correspond with social class. Moreover, this hypothetical pathway might bring more encouraging feedback from teachers, thereby increasing critical features of habitus. 
The usefulness of Bourdieu's notion of cultural capital to the understanding of the reproduction of social class is firmly established (Lareau and Weininger 2003; Calarco 2014; Yee 2014). Although Bourdieu seemed to believe that domination and stratification were endemic to social structures, he nevertheless "railed against the overly deterministic models of social theory, stressing instead the contingent nature of life trajectories and the situated nature of these paths within fields" (Lareau 2015:4). Bourdieu provided a dynamic model of structural inequality, anchored by the notion of cultural capital, which facilitates capturing "moments" of social reproduction. The nature of these moments can be found in the context in which capital is located, the relative efforts and skill employed to activate capital, and the institutional responsiveness to such efforts (Lareau 2003).

\section{Cultural Capital and Parenting}

Current research suggests that a significant mechanism through which the reproduction of social class occurs originates in the many different ways that advantaged parents interact with their children. Throughout Lareau's study, middle-class parents are observed negotiating with their increasingly assertive children, such that the children are characterized as developing a burgeoning sense of agency. In middle-class homes, notes Lareau, the parenting approach is often characterized as a developmental tool. For example, the parents of a middle-class participant regarded conversations and debates as a chance to "promote reasoning and negotiation skills" (2003:130). Conversely, workingclass parents emphasized obedience and deference to authority, such that their children are characterized as developing a sense of constraint (2003). Differences in these parent's interactions by social class, according Lareau, demonstrate a clear incongruence between the culture in working-class homes and the standards of schools, the effects of which 
amount to a sorting mechanism for the transition to adulthood and opportunities throughout the lifespan. Studies have demonstrated that parenting practices, which appear to be robustly shaped by available resources and cultural capital (e.g., education), often mediate the effects of social background on academic achievement (Davis-Kean 2005). According to Lareau (2003), these differences in parenting practices are manifestations of social class-based variations in cultural capital (Liu 2016), such as cultural knowledge, verbal facility, educational credentials, and awareness of the norms of the academic system (Swartz 1997).

Previous research on parenting and the reproduction of inequalities has overlooked two primary factors, according to Calarco (2014): the possibility of active, or deliberate, culture transmission, in contrast to the implicit and automatic transmission model, and how these active efforts contribute to social reproduction. Using data from a longitudinal ethnographic sample of middle and working-class families, Calarco (2014) found varying types and extent of parental "coaching" efforts related to their elevated positions in the status hierarchy, and these status positions impacted children's school relationships and children's comfort in navigating this setting. Specifically, due to their educational attainment and occupational status, middle-class parents often perceived themselves as equally or more qualified than teachers to make decisions about their child's future. This led middle-class parents to provide "direct and forceful" coaching to their children on how to intervene in school; conversely, working-class parents encouraged their children not to pester or annoy the teacher (Calarco 2014).

These different "activation processes," reports Calarco, advantage middle-class children, as teacher responses to children's problem-solving strategies affect their 
chances for success. These patterns indicate that social status positions shape subsequent parental logics of action, alternatively categorizing similar child behaviors as appropriate for success (e.g., middle class) or pestering (e.g., working class), with clear advantages for middle-class students. Lareau's $(2003 ; 2015)$ research on parenting approaches similarly indicates that social location compels parents to create different paths for academic success. Whereas working-class parents appear to depend heavily on teachers to educate their child, middle-class parents are more likely to supplement what teachers deliver and supervise and monitor their children's educational experiences. This provides a middle-class parental advantage with teachers, as teachers tend to actively solicit parental participation, which in turn leads to advantages for middle-class children and their relationships to teachers (Lareau 1987). Much research demonstrates that upwardly mobile adults often have "cultural guides" (e.g., teachers, coaches, relatives, or friends) who help decode institutional rules of the game, give advice, and intervene at crucial moments (Stephens et al. 2014; Lareau 2015).

One of the primary differences between class-based parenting styles is the quantity and quality of parental investments. These differences figure largely in the transition to adulthood, as parental investments of time in enriching activities are significant predictors of children's success: “The long shadow of family disadvantage inheres in the resource limitations families suffer and the consequences that follow" (Alexander et al. 2014:34). The results of four consumer expenditure surveys conducted between the early 1970s and 2005 to 2006 indicate that spending on "child-enrichment goods and services" increased for families in the top quintile to a much greater extent than for those in the bottom income quintile (Kornich and Furstenberg 2013). Whereas in 
the early 1970s high-income families spent approximately $\$ 2,700$ more per year on childenrichment than low-income families, by 2006 this gap had increased to $\$ 7,500$.

In a study assessing changes in parental spending on children between 1972 and 2007, Kornich and Furstenberg (2013) report a class-based gap in spending for a variety of enrichment activities, including books, computers, music lessons, summer camp, travel, school supplies, extracurricular activities, recreation, and leisure. Once they controlled for parental income, disparities by parental education were significantly increasing, meaning that children of high-income and educated parents have been doubly advantaged, and children of low-income and less educated parents have been doubly disadvantaged. These class-based differences in exposure to enrichment activities may account for part of the gap in background knowledge between low and high-income children that appear to be predictive of verbal fluency in middle school.

Although parents at all income and educational levels appear to be spending more time with their children than parents several decades ago, the increase is significantly higher for parents with a college education, and the increase in time spent with children appears to be concentrated around development activities in particular (Altintas 2015). According to a recent analysis on the widening education-gap in U.S. developmental child-raising, during the 1970s there were very little class-based differences in parental time spent with children. However, by 2013, young children of college-educated parents were getting double the amount of time spent with parents, and double the amount of development-facilitating interactions, as children of high-school educated parents. In particular, highly educated mothers appear to be especially efficient in their parental time 
investments, consistently tailoring their specific activities to children's developmental stage (Altintas 2015; Lareau 2003; Bodivski and Farkas 2008).

\section{Concerted Cultivation}

Lareau (2003), through her nuanced ethnographic study of the reproduction of social class, sought to make "the invisible visible through a study of pleasures, opportunities, challenges, and conflicts in the daily lives of children and their families" (13). Theoretically framing her investigation and subsequent reasoning in the work of Bourdieu, Lareau contends that social class is characterized by its "habitus," or its own particular ways of thinking and behaving, which Lareau describes as "class-specific dispositions."

Lareau (2003) describes how social class based cultural patterns, habits, and skills are created and reinforced by different parenting approaches and suggests that the alternative approaches to parenting explains part of the mechanism by which social class is reproduced. According to Lareau, middle and upper-class parents practice a "concerted cultivation" style, characterized by deliberately nurturing in their children the skills and habits viewed as constitutive of success in schools and beyond. Children in these families spend considerable time in structured activities administered by adults (e.g., music, sports, clubs). Lareau observed poor and working-class parents using a less hands-on approach, which she described as "natural growth," characterized by a view of parenting in which parents provide the essential elements for development (e.g., food, security, love), but in other areas allow children to develop on their own. Children in these families spend considerable time playing informally with other children and watching television. 
Lareau (2003) reports differences in parenting style by social class in four essential areas for educational success and the transition to adulthood: perceptions of parental responsibility, the use of language in the home, organization of extracurricular activities, and parental readiness to intervene in school on behalf of their children. The concerted cultivation approach, in each of these four areas, appears to have both quantitative and qualitative advantages for middle class children who have more activities than their working-class peers, more frequent and nuanced verbal interactions, and a higher number of parents who perceive their role as institutional intervener and who are prepared to successfully do so at school. According to Lareau (2015), it is not a coincidence that the concerted cultivation approach corresponds with institutional norms in schools requiring parents and children to be actively involved to maximize opportunities. Recent research has documented social class-based differences relative to getting out of chairs in class to ask for help (Calarco 2011), and parental coaching of children to intervene in schools (Calarco 2014), including coaching children on how to successfully navigate a large, public university (Yee 2014).

For Lareau, differences in parental style are both meaningful and predictable. Following Bourdieu, Lareau asserts that individuals are socialized differently relative to their social location. This socialization in turn provides children with a sense of what is comfortable and natural (i.e., habitus). Differences in habitus give the children different cultural skills, social connections, educational practices, and other cultural resources, which translate into different benefits as individuals move out into the world (Lareau 2003). 
Cheadle and Amato (2011) conducted a quantitative analysis of nationally representative data to investigate Lareau's qualitative conclusions related to concerted cultivation. They found a pattern of strong associations between children's participation in extracurricular activities, parental involvement with schools, and the presence of educational materials in the home, each of which corresponds with the concerted cultivation construct. Additionally, their analysis supports Lareau's contention that social class is a fundamental characteristic of parents' use of concerted cultivation; social class independently accounted for close to $50 \%$ of the variance in concerted cultivation. Overall, the analysis by Cheadle and Amato (2011) is consistent with Lareau's theoretical position, indicating that concerted cultivation is a "higher-order" strategy that organizes parental involvement across several domains.

Bodovski (2010) employed a similar approach to Cheadle and Amato (2011), using a nationally representative study to quantitatively examine the determinants and consequences of concerted cultivation practices among White and African American students. Bodovski's findings generally support Lareau's model, demonstrating positive and strong associations between parental social class and concerted cultivation. Specifically, Bodovski's results demonstrate that parental social class and educational expectations (attitudes) are positively associated with the concerted cultivation strategy (actions), and that this cultivation is connected with increased school achievement (2010). Moreover, Bodovski's findings confirm Lareau's contention that parents practice more extensive concerted cultivation because their own educational and occupational experiences appear to compel them to want high levels of educational achievement for their children, thereby contributing to class-based social reproduction. 
Literature in the sociology of education has repeatedly demonstrated that social class origins shape outcomes across the lifespan in formative ways. Lareau's perspective on the cultural logics of parenting, and the concerted cultivation practices of middle-class families in particular, are especially relevant in today's economic and educational system. Whereas concerted cultivation practices closely align with the standards and expectations of critical institutions, the practices of working-class parents "are not fully in sync with the institutional standards of schools" (Lareau 2003:311).

The research indicates that Lareau's concerted cultivation framework for parenting continues to be a highly useful perspective on the reproduction of social class, as it illumines and organizes with clarity the pivotal role that specific, cumulative parental strategies play in key life transitions, identifying critical resources that appear to profoundly shape the lifespan effects of social class.

\section{Parenting and Non-Cognitive Factors}

The cultural capital model of Lareau has focused on parenting (2003) and cultural knowledge (2015) as mechanisms connecting social class background to academic outcomes, but relatively little is known about the impact of parenting, and concerted cultivation in particular, on shaping academically-related strategies, beliefs, and behaviors that correspond with academic success, including non-cognitive factors like positive behaviors, behavior problems, and a sense of mastery we know to be facilitative of academic success (Farrington et al. 2012). What appears clear is that non-cognitive factors are not fixed at birth, and indeed develop as one interacts with social environments, particularly early in life in the context of parenting and family relationships (Bowles et al. 2001). 
In a review of the literature of family impact on student motivation, Grolnick et al. (2009) report that parents play a pivotal role shaping children's sense of competence, mastery, motivation, and positive affect. In a study by Wang and Eccles (2012) on the impact of parental social support on student motivation, parent social support was positively correlated with students' positive behaviors, extracurricular activities, interest in school, and intrinsic motivation, and parental social support was a more impactful predictor than peer support for three of these indicators.

Lewis et al. (1999) suggest that the family and parenting environments in higher social class background homes lead to children possessing a greater sense of mastery because of the more nuanced problem solving and life skills fostered in these homes. Many lifespan developmental approaches adopt a similar perspective, framing child development as an unfolding process within a context of socioeconomically influenced family interaction patterns (Caspi 2002). In a recent study by Shanahan et al. (2014), noncognitive factors moderated the impact of family socioeconomic effects on social attainment for children, indicating that non-cognitive factors are more important for upward social mobility for children and adolescents from lower socioeconomic households.

Research indicates that varying social context factors and differences in parenting practices contribute to children's development. McLanahan (2004) reports that children in lower socioeconomic households benefit less from those parental investment activities, attention, and resources that are especially facilitative of soft-skill development than children in higher socioeconomic households. Heckman (2011) reports related findings, noting that mothers from lower socioeconomic households talk to their children and read 
to them less, are less encouraging, employ more rigid parenting approaches, and are less engaged with children's academic work than mothers from higher socioeconomic households. In other words, “....children from disadvantaged families tend to have fewer opportunities at home to foster competence, encourage them to find interest or see value in learning, promote autonomous learning, or develop social relationships that support and value achievement" (Center on Education Policy 2012:5).

Although the exact pathways connecting parenting to non-cognitive factors in children are not entirely known, there is a growing body of research identifying the social processes and interactions in the family as key to non-cognitive development. These parental socialization processes are fostered within and shaped in various ways by their relative location in broader socioeconomic structures like capitalist labor markets and educational systems employing questionably reliable standardized testing (Bowles and Gintis 2011; Au 2013). One of the central goals of this study is to connect the socialization practices of parents, or habitus, to the school context, and to provide clarity on the intersecting experiences of children in these two institutional settings, particularly the ways through which parenting behaviors may connect to children's non-cognitive behaviors and academic performance. As Bowles et al. (2001) note in their analysis of the determinants of earnings, “...the contribution of schooling and parental socio-economic status to earnings is in part explained by earnings-enhancing behaviors learned or genetically transmitted from parents" (Bowles et al. 2001:1171).

\section{Non-Cognitive Factors and Academic Achievement}

There is an increasing understanding that much of what grades measure are domains that extend beyond mere content knowledge and academic skills, including 
academically-related strategies, beliefs, and behaviors that correspond with educational success, including non-cognitive factors like work habits and perseverance, problem solving, and social skills (Conley 2007; Stankov et al. 2013). According to Liu (2016), these non-cognitive factors contribute to a widening socioeconomic achievement gap through two central pathways: non-cognitive factors are typically stratified by family socioeconomic status upon school entry for children, and these non-cognitive factors positively impact learning in a cumulative fashion throughout one's time in school. Therefore, by virtue of their socialization advantage, children from higher socioeconomic family backgrounds are sorted upon school entry into a more advantageous learning and developmental trajectory. Non-cognitive factors like self-regulation and mastery are essential skills for early academic achievement, and if higher socioeconomic status children are able to more consistently employ these skills, in the long run they will be better learners than lower socioeconomic status peers because the payoff of their early start compounds grade by grade.

In their model on the production of human capabilities, Cunha and Heckman (2009) identify skill formation as a cumulative process, inextricably connected to our life history. Accordingly, early life or beginning of school advantages in non-cognitive factors are theorized to be indefinitely maintained without interventions to disrupt this advantage. For example, these non-cognitive factor advantages may lead to deeper engagement in school by virtue of higher self-regulatory capacity and the cultivation of positive relationships with institutional gatekeepers in that setting by virtue of cultural familiarity, both of which reinforce a sense of belongingness and loop back to everincreasing engagement as their socialization practices are positively reinforced and 
rewarded. Cunha and Heckman (2009) report that non-cognitive factors facilitate the cultivation of cognitive skills at each development period that connects childhood to adolescence.

Bowles and Gintis's (1976) notion that school curriculums and classroom dynamics reflect the differential organization of social class-based dispositions and skills, and that these are transmitted intergenerationally, remains a highly useful contribution, as it has been empirically confirmed by a number of studies (Collins 2009; Bowles et al. 2001; Shanahan et al. 2014; Heckman and Kautz 2012). Bowles et al. (2001) report that the relationship between parent's SES and their adult children's wages remained significant after controlling for children's years of education, school quality, and cognitive test scores. They found that employers would pay a wage premium on “incentive-enhancing preferences" related to productivity and the likelihood that employees would honor contracts. Recent research by Shanahan et al. (2014) and others (Heckman and Kautz 2012) indicate that these non-cognitive attributes significantly explain the intergenerational transmission of social class, as high socioeconomic parents possess incentive-enhancing preferences and transmit them to their children.

The Wisconsin model of status attainment provides another model theorizing a connection between non-cognitive factors and academic achievement. Developed with the intention of clarifying the causal mechanisms transmitting family advantages (or disadvantages) to the next generation, Sewell et al. (1970) posit that particularly in educational and occupational contexts, the primary causal mechanisms are non-cognitive in nature. In this model, although material resources and cognitive ability play a role in the intergenerational transmission of advantage, the social background family effects on 
academic achievement are mediated by social-psychological factors such as conscientiousness (Hauser et al. 1983; Sewell and Hauser 1975).

Recent research suggests that a range of social-psychological skills or noncognitive factors are strongly linked to academic achievement, including skills and beliefs associated with three domains: positive behaviors, behavior problems, and sense of mastery (Farrington et al. 2012; Heckman and Rubenstein 2001; Bowles and Gintis 1976; Reardon and Portilla 2014; Hsin and Xie 2016).

Positive behaviors, behavior problems, and mastery. Positive behaviors constitute those social skills that improve social interactions, like those with teachers or between peers. Although the development of interpersonal skills and a pattern of prosocial behavior may not be explicit academic goals, they impact the relational and social learning climate for children. Wentzel (1991) characterized socially responsible behavior such as conforming to social rules and role expectations as facilitative of academic achievement because it develops social contexts for learning. In other words, social skills often function as enablers in academic settings. There is evidence that elements of sociability and cooperativeness have positive effects on academic achievement, but much of this research examines other non-cognitive factors in combination with these two elements. In a longitudinal study that measured students in grades one, three, and six, and again at age 16, Teo et al. (1996) report that socioemotional functioning in school was determinative of academic achievement scores at each assessment point. Similarly, a meta-analysis on social and emotional learning school-based interventions from kindergarten through high school reports positive effects of these interventions on academic achievement (Durlak et al. 2011). 
In a study assessing the relationship between academic achievement and peer and teacher ratings of social behavior, Wentzel (1993) found that GPA and standardized test scores were significantly related to both positive behavior and behavior problems. Additionally, positive behavior, behavior problems, and academic behavior were all significantly correlated with one another, as well as to family structure.

Results from a meta-analysis examining predictors of early reading achievement found that behavior problems were one of the factors predicting early school achievement (Horn and Packard 1985). Horn and Packard report that the studies collectively indicate that positive behaviors and behavior problems, particularly internalizing behavior problems, have a meaningful relationship and often a direct effect on achievement in school.

Invariably there is some measure of conceptual overlap when attempting to isolate individual non-cognitive factors from related concepts (Farrington et al. 2012), and that is the case with mastery. Mastery, defined as having a sense of control over the forces that impact one's life (Pearlin and Schooler 1978), shares common features with self-efficacy (Bandura 1977) but, according to Skinner (1996), is a more encompassing and global psychological component of human functioning. Mastery has been demonstrated to be a significant predictor of psychological and physical wellbeing throughout the lifespan (Skinner 1996; Conger et al. 2009), with perceived mastery and control acting as a more significant predictor of functioning than actual control. According to Conger et al. (2009), mastery is a pivotal indicator of how someone will respond to daily situations as well as challenges, serving as an adaptive problem solving resource. In the academic realm, mastery has functioned as a predictor of changes in grades and achievement and 
has even been demonstrated to close achievement gaps created by lower IQ scores (Duckworth and Seligman 2005; Duckworth et al. 2010).

Despite decades of research on the positive impact of mastery, little is known about the cultivation of mastery in children. Lewis et al. (1999) theorized that children from higher SES homes likely develop more adaptive mastery approaches because of the presumed higher level of problem solving in a more enriched family setting, and that the social interactions and outcomes therein provide a steep mastery-related socialization advantage.

Two concepts, perseverance and self-control, which are related to and perhaps to some extent captured within mastery, are defined in different ways in the academic context. Dweck et al. (2011) describe these factors as encompassing the degree to which students work to complete tasks despite resistance or obstacles. In the context of learning and achievement, Dweck et al. (2011) describes this as a form of "academic tenacity," characterized by mindsets and skills that help students to look past short-term concerns to longer-term or "higher-order" goals, and to endure through challenges and setbacks while continuously pursuing these goals. In cross-sectional studies perseverance has shown moderate connections to academic achievement (Farrington et al. 2012).

Another closely related concept to mastery, self-efficacy, involves student beliefs about their capacity to succeed at a task. According to Bandura (1986), individuals will engage in activities in which they feel a sense of confidence about their capacities, and conversely will avoid activities in which they lack this confidence. Research suggests that self-efficacious beliefs motivate students to persist with school work, which in turn leads to increased academic achievement (Walton and Dweck 2009). In a summary of 
empirical findings on non-cognitive influences on academic achievement using two international datasets, Lee and Stankov (2016) report that confidence was the strongest predictor of individual and country-level academic achievement from over 200 noncognitive factors.

In a review of the literature on the role of non-cognitive factors in shaping school performance, Farrington et al. (2012) report that the literature suggests that students tend to have increased academic achievement when they demonstrate perseverance and academic behaviors requiring mastery and self-control; and that cultivating masteryrelated attitudes and learning strategies, including features of sociability and cooperativeness, are the most effective ways to develop perseverance.

Successfully addressing the preconditions for learning appears to be central to the rationale for how non-cognitive factors operate in academic settings, and thereafter in the labor market. The research suggests that students must think of themselves and school in a way that motivates learning and must also regulate themselves and socialize in ways that facilitates learning via cooperation, demonstrating initiative, and partnering with fellow students and authority figures.

This study theorizes that concerted cultivation facilitates the acquisition of noncognitive factors that may serve as preconditions for learning for middle and upper-class children, leaving working-class children less equipped to thrive in academic settings. The research of Dweck et al. (2011) suggests that it is less advantaged students who respond most significantly from interventions targeting non-cognitive factors because it is often these non-cognitive factors that are serving as barriers (Durlak et al. 2011). 
Independently, non-cognitive factors and parenting style, particularly concerted cultivation, significantly determine educational and economic mobility. However, we do not know if the concerted cultivation parenting approach serves as a pathway to the acquisition of non-cognitive factors shaping achievement in school. Using data from a nationally representative sample of students, this study will provide an analysis that addresses this gap in the literature. 


\section{Chapter 3: Methods}

Sample

This study uses secondary data analysis on the Panel Study of Income Dynamics (PSID) and its Child Development Supplements (CDS-I and II) and Transition to Adulthood (TA) Study. The PSID has collected data on a range of issues including employment, income, wealth, expenditures, health, marriage, childbearing, child development, education, and many other topics since 1968. These data are especially useful to examine my research questions because of the richness of the PSID information. The PSID data includes parent/caregiver, teacher, and student interviews on a range of aspects of achievement, behavior, and wellbeing, and provides information on school, teacher, and classroom dynamics. PSID researchers have also completed general knowledge, math, and reading student assessments using standardized grade-appropriate test items.

In 1997, the PSID supplemented its primary data collection with additional data on a sample of birth to 12 -year-old children and their parents. The objective was to provide researchers with a comprehensive, nationally representative, and longitudinal data base of children and their families with which to study the dynamic process of early human capital formation. The CDS-I successfully completed interviews with 2,394 families (88\%), providing information on 3,563 children. In 2002-2003, the CDS recontacted families in CDS-I who remained active in the PSID panel as of 2001 for CDSII, and again in 2007-2008 for CDS-III.

The TA study was initiated to bridge a gap between the data collected in the PSID, primarily on adults who have started their own families, and the data collected in the 
CDS supplement on co-resident children up to age 18. Currently, CDS youth participate in three rounds of TA data collection (ages 18-24), and then at approximately 25 years of age join the core PSID and participate in the study every other year from that point forward.

I took advantage of this design by using data linked by the PSID administrators from the 2009 to 2011 TA Study to the CDS-I (1997), CDS-II (2002), and 1997 PSID to examine the hypothesized relationships from late childhood/early adolescence (CDS-I) to adolescence (CDS-II). Response rates for the 1997 PSID, CDS-I, CDS-II, and 2009 and 2011 TA Study are 90, 88, 91, 92, and 92 percent (Panel Study of Income Dynamics 2013).

The analysis includes CDS-I children in 1997 who meet a range of criteria. Only children whose mothers were identified as the primary caregiver for the child are included (the mother is identified as the primary caregiver for more than 95 percent of participating children). Additionally, children in the analytic sample were six to 13 years of age in the 1997 CDS-I, and therefore a minimum of 22 years old in the 2009 or 2011 TA Study. After restricting the sample to those who meet these criteria $(N=3,563)$ and including only those with valid responses on the dependent variables (Reading Score and High School GPA) and complete data for all variables, the final analytic sample consists of 791 respondents.

\section{Variables}

Independent variables. The first independent variable in this study is social background, as measured by mother's education. Although social background is often captured by parental occupation or income (Roksa and Potter 2011), education is a 
theoretically salient aspect of social background for an educational performance and mobility study. I have employed the same approach as Carolan and Wasserman (2015), operationalizing social background as mother's education on a range from zero to 17 , with each unit corresponding to the number of grades completed, and 17 equaling at least some postgraduate work. The educational focus on mothers rather than fathers is due to mothers functioning predominantly as children's primary caregivers (Lareau and Weininger 2008), spending more time than fathers in this role, and assuming greater general responsibility for parental caregiving (Roksa and Potter 2011).

The second independent variable in this study is a measure of educational expectations mothers have for their child, reported on by mothers in the CDS-I's primary caregiver module in 1997. Participants responded to the prompt, "How much schooling do you expect that (child's name) will complete?" This variable is scaled from 1 to 8 in the PSID, with 1 representing less than high school and 8 representing a Ph.D. or other doctoral degree.

The third independent variable in this study is concerted cultivation, a variable constructed by Carolan and Wasserman (2015) from items taken from the CDS-I's primary caregiver module in 1997 using confirmatory factor analysis (CFA) (Bollen 1989). This concerted cultivation model developed by Carolan and Wasserman (2015) is comprised of four observed summed scores related to the concerted cultivation-related domains identified by Lareau (2003) and used by Bodovski and Farkas (2008) to construct their composite measure. According to Carolan and Wasserman, "the standardized factor loadings and goodness of fit statistics give us confidence that we have constructed an empirical measure that reflects the richness of Lareau's original 
conceptualization and substantively matches other notable efforts to create an empirical measure of this latent construct" (175). The four domains are parental involvement, parental responsibilities, language patterns, and leisure activities, used in this study because they link most closely to previous quantitative assessments of concerted cultivation (Bodovski and Farkas 2008; Carolan 2015; Carolan and Wasserman 2015). The first domain, parental involvement, reflects the sum of five items: volunteered at school, informal talk with teacher, informal talk with principal, attended a school event, attended a parent-teacher association meeting, each measured from 1 to 3 , with 1 representing "not in the current school year," 2 representing "once," and 3 representing "more than once." The second domain, parental responsibilities, reflects the sum of three items: obtain information about the teacher prior to the school year, meet with the teacher, request a teacher, coded 1 if yes, or 0 otherwise. The third domain, language patterns, reflects the sum of three items: discuss interests with child, discuss studies with child, discuss school with child, measured on a scale from 1 to 4 , with 1 representing "never," 2 representing "rarely," 3 representing “occasionally," and 4 representing "regularly." The fourth domain, leisure activities, assesses extracurricular participation and hobbies and reflects the sum of two items, coded 1 if the youth's mother reported participation, and 0 if not.

Dependent variables. The first dependent variable in this study is a standardized cognitive ability assessment based on a reading comprehension score (reading score) that is used as one of two measures of academic achievement. This score is constructed using a child's standard score on the Woodcock Johnson Revised (WJ-R) passage comprehension test of achievement administered as part of the CDS-II in 2002. WJ-R 
achievement tests are highly respected standardized cognitive assessments (Woodcock et al. 2001). The WJ-R passage comprehension test has been normed by PSID researchers to correspond to a child's performance in comparison with national averages for a child's age. Building on the model employed by Carolan and Wasserman (2015), this study uses the passage comprehension test because reading is a central skill for a range of academic areas; moreover, reading appears to be less sensitive than math to classroom instruction (Durik and Eccles 2006).

High school grade point average (high school GPA) serves as the second measure of academic achievement and one of the dependent variables in this study. Using both the 2009 and 2011 TA Study, high school GPA was developed by dividing a child's selfreported grade point average by the maximum possible average in her or his high school and then transforming the number into a $z$ score. Since high school GPA is based in part on teachers' ratings of a student's performance, this measure is related to both cognitive and non-cognitive skills, including those that are rewarded in academic settings (e.g., mastery and persistence), and is considered a meaningful determinant of postsecondary academic and non-academic success (Noble and Sawyer 2004; Zwick and Sklar 2005; Planty et al. 2006).

Using these two measures of academic achievement provided the opportunity to assess achievement at two meaningfully different developmental time points for students (Wang and Eccles 2012), as well as the ability to clarify the non-cognitive behavioral impact that high school GPA would be seemingly more likely to capture given its partial reliance on teacher assessment of student behavior. Moreover, although to some degree both standardized tests and GPA impact academic outcomes and transitions into the labor 
market, research suggests that GPA appears to function as a more robust predictor of academic and labor market outcomes than standardized achievement measures (Betts and Morell 1999).

Mediator variables. Central to my argument is that the influence of parenting style on academic achievement is mediated by non-cognitive factors. Accordingly, three non-cognitive factors are used as mediating variables in this study: positive behaviors, behavior problems, and mastery. These mediating variables are used in the fourth model to address the research question: To what degree do non-cognitive factors mediate the relationship between concerted cultivation and academic achievement? However, the three non-cognitive factor variables are used as dependent variables in the second model to address the research question: To what degree is parenting, specifically concerted cultivation, associated with non-cognitive factors in school? In the third model, the three non-cognitive factor variables are used as independent variables to address the research question: To what degree are non-cognitive factors associated with academic achievement? Each of the three non-cognitive factor measures are completed by a child's primary caregiver reporting on the child.

Positive behaviors. Positive behaviors are assessed using The Positive Behaviors Scale (PBS) (Polit 1998). The scale used in the PSID consists of 10 items (Cronbach's alpha of .79) completed by a child's primary caregiver that reads: "Please tell me how much each statement applies to (CHILD) on a scale from 1-5, where one means 'not at all like your child,' and five means 'totally like your child,' and two, three and four are 'somewhere in between"” (e.g., "Thinks before (he/she) acts, is not impulsive"). Caregivers also reported whether their child "Is cheerful, happy;" "Is warm, loving;" "Is 
curious and exploring, likes new experiences;" "Gets along well with other kids;" "Can get over being upset quickly;" "Is admired and well-liked by other kids;" "Does things for (him/her)self, is self-reliant;" "Waits his or her turn during activities;" "Thinks before he or she acts, is not impulsive;" "Usually does what I tell (him/her) to do."

Behavior problems. Behavior problems are assessed using The Behavior Problems Index (BPI). The BPI measures the incidence and severity of child behavior problems (Peterson \& Zill 1986). The BPI is based on responses by the primary caregiver (Cronbach's alpha of .90) for children three years and older as to whether a set of 30 problem behaviors was often, sometimes, or never true of the target child. Behaviors included relate to sudden mood changes, anxiousness, meanness towards others, and obsessiveness. These factors have been demonstrated to be negatively correlated with prosocial non-cognitive factors such as sociability and cooperativeness, and perseverance (Dweck at al. 2011; Heckman and Rubenstein 2011).

Mastery. Mastery is assessed using The Pearlin Mastery Scale (Pearlin and Schooler 1978). This measure (Cronbach's alpha of .76) assesses the extent to which people see themselves as having control over aspects of their lives. This measure consists of the four following items answered on a 4-point response scale ("Strongly Agree," "Agree," "Disagree," "Strongly Disagree"): "There is really no way I can solve some of the problems I have," "Sometimes I feel that I'm being pushed around in life," "I have little control over the things that happen to me," and "I often feel helpless in dealing with the problems of life." 


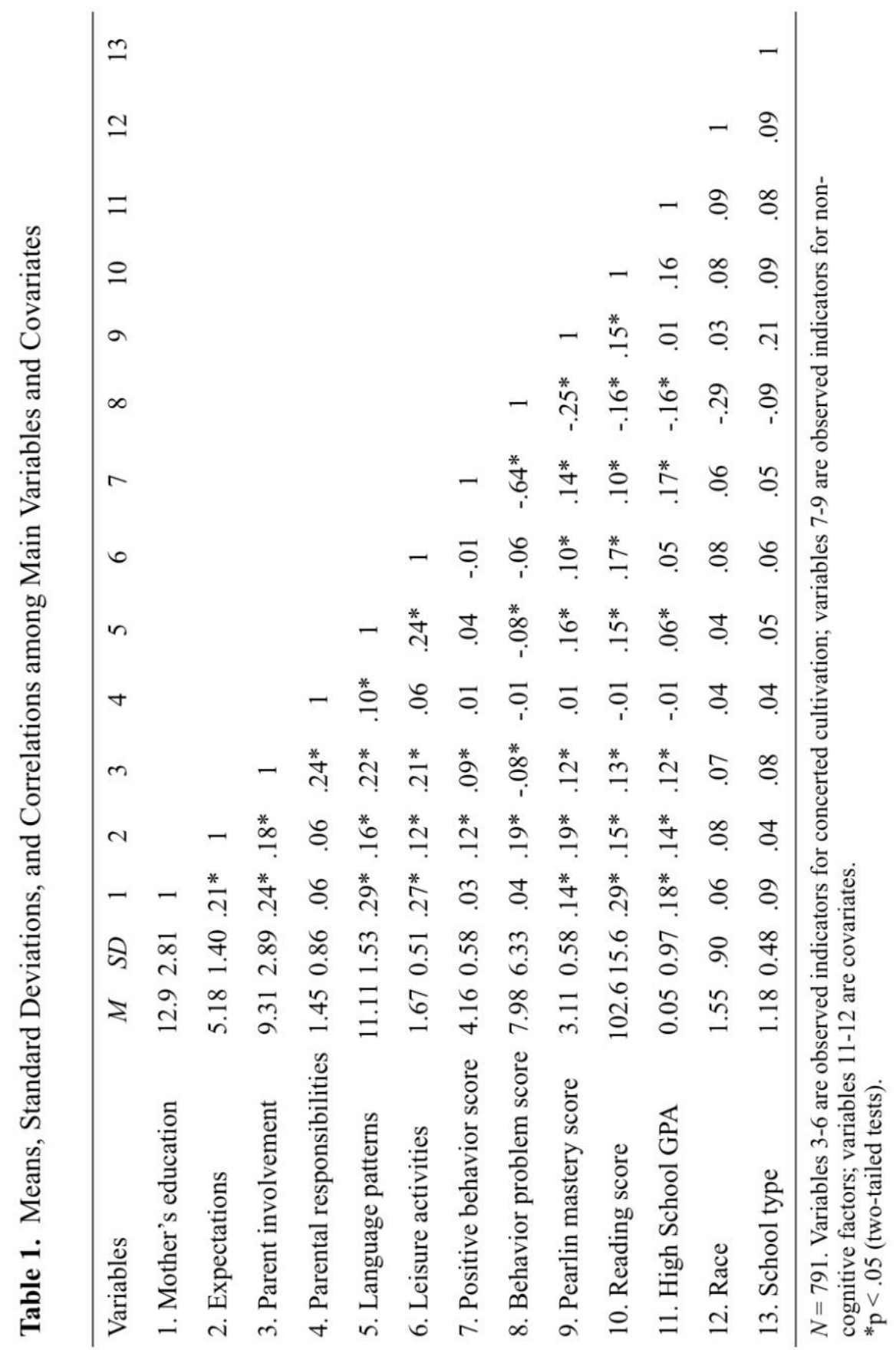




\section{Analytic Plan}

Descriptive statistics are provided for all variables in the study (Table 1). To facilitate interpretation of multivariate analyses, bivariate analyses are used to establish baseline relationships between parents' concerted cultivation and child's non-cognitive factors, as well as between child's non-cognitive factors and child's academic achievement. Linear regression models are used to estimate the effect of mother's education and educational expectations on non-cognitive factors (Research Question 1). The second model uses linear regressions to estimate the effects of parent's concerted cultivation on non-cognitive factors (Research Question 2). The third model uses linear regressions to analyze the estimated effects of non-cognitive factors on academic achievement (Research Question 3). The fourth model uses a path analysis to analyze whether non-cognitive factors mediate the relationship between concerted cultivation and academic achievement (Research Question 4). A primary advantage of this approach over standard regression approaches is that the path model tests all indirect and direct effects simultaneously (Li 2011).

Covariates. In order to minimize concerns of spurious associations, the models in this study include race (a dummy variable for white, $1=$ yes, $0=$ no) and type of school (a dummy variable for school type, $1=$ public, $2=$ private) as covariates taken from the CDS-I. Means of the variables are show in Table 1. The mean score for mother's education is 12.9 , and the mean score for educational expectations is 5.18 . For the concerted cultivation variables, the average school involvement score is 9.31 ; average parental responsibilities score is 1.45 ; average language patterns score is 11.11 ; and the average leisure activities score is 1.67 . For the non-cognitive factor variables, the mean 
positive behavior rating is 4.16 ; mean behavior problem rating is 7.98 ; and the mean mastery score rating is 3.11 . For the academic achievement variables, the mean reading score is 102.6 , and the mean high school GPA rating is 0.05 . For the covariates, the mean race score is 1.55 , and the mean school type score is 1.18 . 


\section{Chapter 4: Results}

Although there are mixed findings reported in Figure 2, model fit tests indicate that an adequate model has been constructed. The model produced a significant chisquare, but this is typically the case with samples larger than 400 (Kenny 2015). Additional global fit indices were well within acceptable ranges, with an SRMR less than .08, and a CFI greater than .90 (McDonald and Ho 2002). 


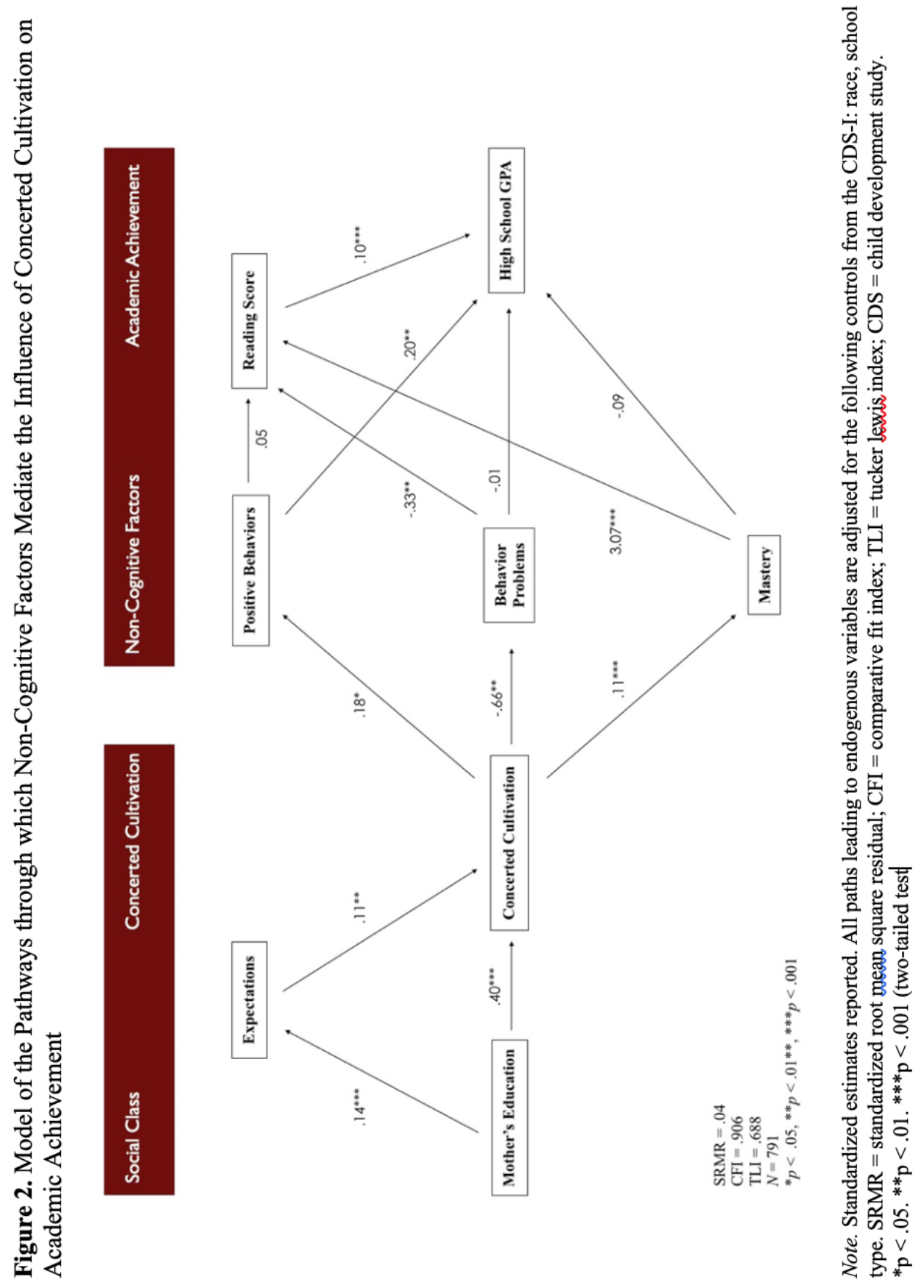


Table 2 reports the findings of the first research question related to the role of mother's education and educational expectations in shaping concerted cultivation, including the standardized path coefficients for all direct relationships so that estimates are comparable. 


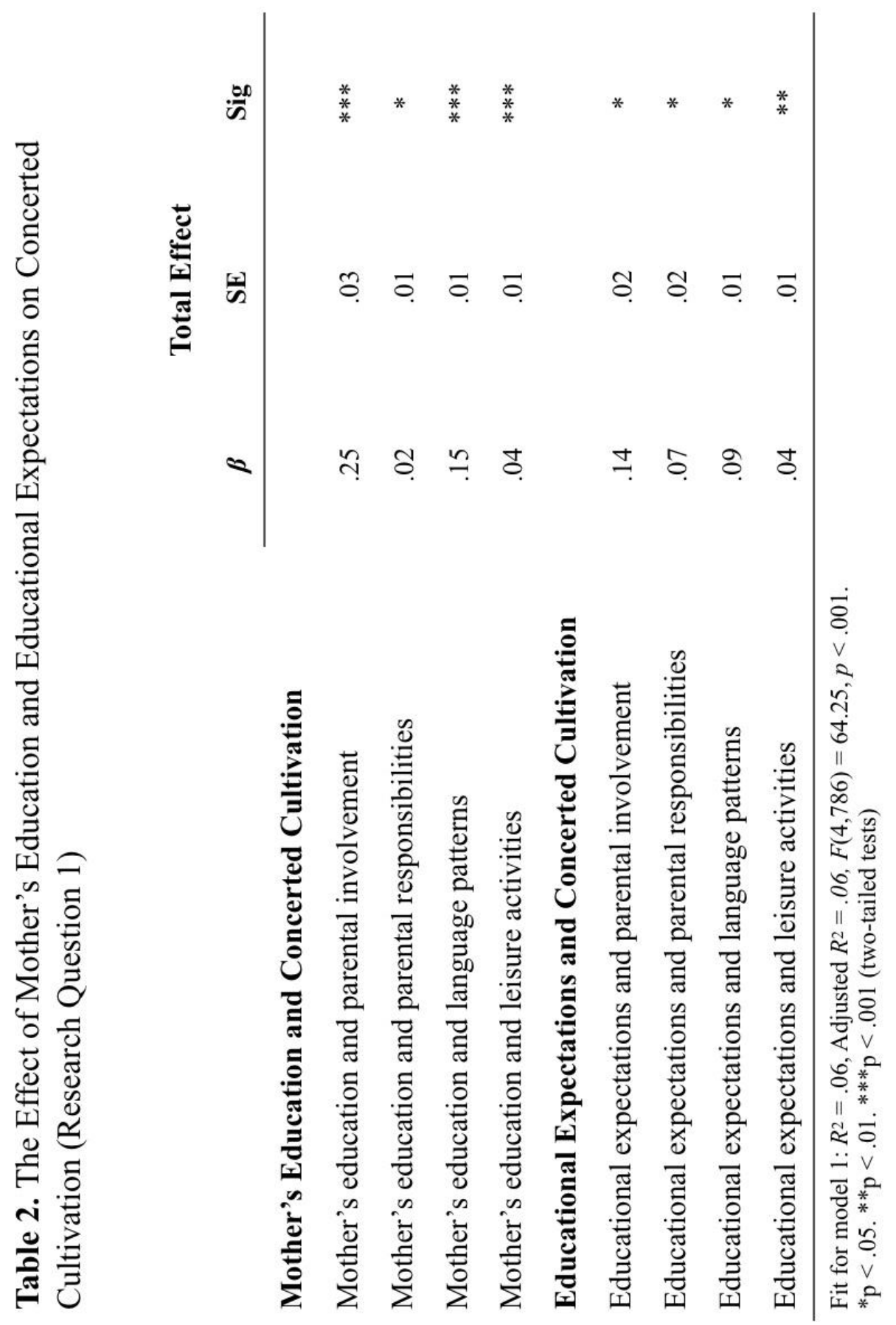


Consistent with recent research (Lareau 2003; Bodovski and Farkas 2008;

Carolan 2015; Carolan and Wasserman 2015), social background, as measured by mother's education, is positively and significantly associated with educational expectations $(B=.14, z=3.35, p<.001)$ and the concerted cultivation model $(F(5,785 ; p$ $<$.001). Additionally, mother's education is positively and significantly associated with all four concerted cultivation domains: parental involvement $(B=.25, z=2.85, p<.001)$, parental responsibilities $(B=.02, z=.95, p<.02)$, language patterns $(B=.15, z=2.05, p$ $<.001)$, and leisure activities $(B=.04, z=1.15, p<.001)$. Although not as strong a predictor as mother's education, educational expectations are also positively and significantly associated with all four concerted cultivation domains: parental involvement $(B=.14, z=2.88, p<.04)$, parental responsibilities $(B=.07, z=1.92, p<.05)$, language patterns $(B=.09, z=2.12, p<.05)$, and leisure activities $(B=.04, z=.68, p<.006)$. These are relatively strong coefficients, particularly the pathway from mother's education to the concerted cultivation model $(B=.40)$, which validates Lareau's contention that the behaviors comprising concerted cultivation are characteristic of parents with social and educational advantages who have higher educational expectations for their children.

Table 3 reports the findings of the second research question related to the role of concerted cultivation in shaping non-cognitive factors. The path model includes the standardized path coefficients for all direct relationships so that estimates are comparable. In line with the work of Lareau (2003), this model demonstrates support for the second hypothesis regarding the relationship between concerted cultivation, as measured by school involvement, parental responsibilities, language patterns, and leisure activities, 
and non-cognitive factors, as measured by positive behavior, behavior problems, and mastery. 


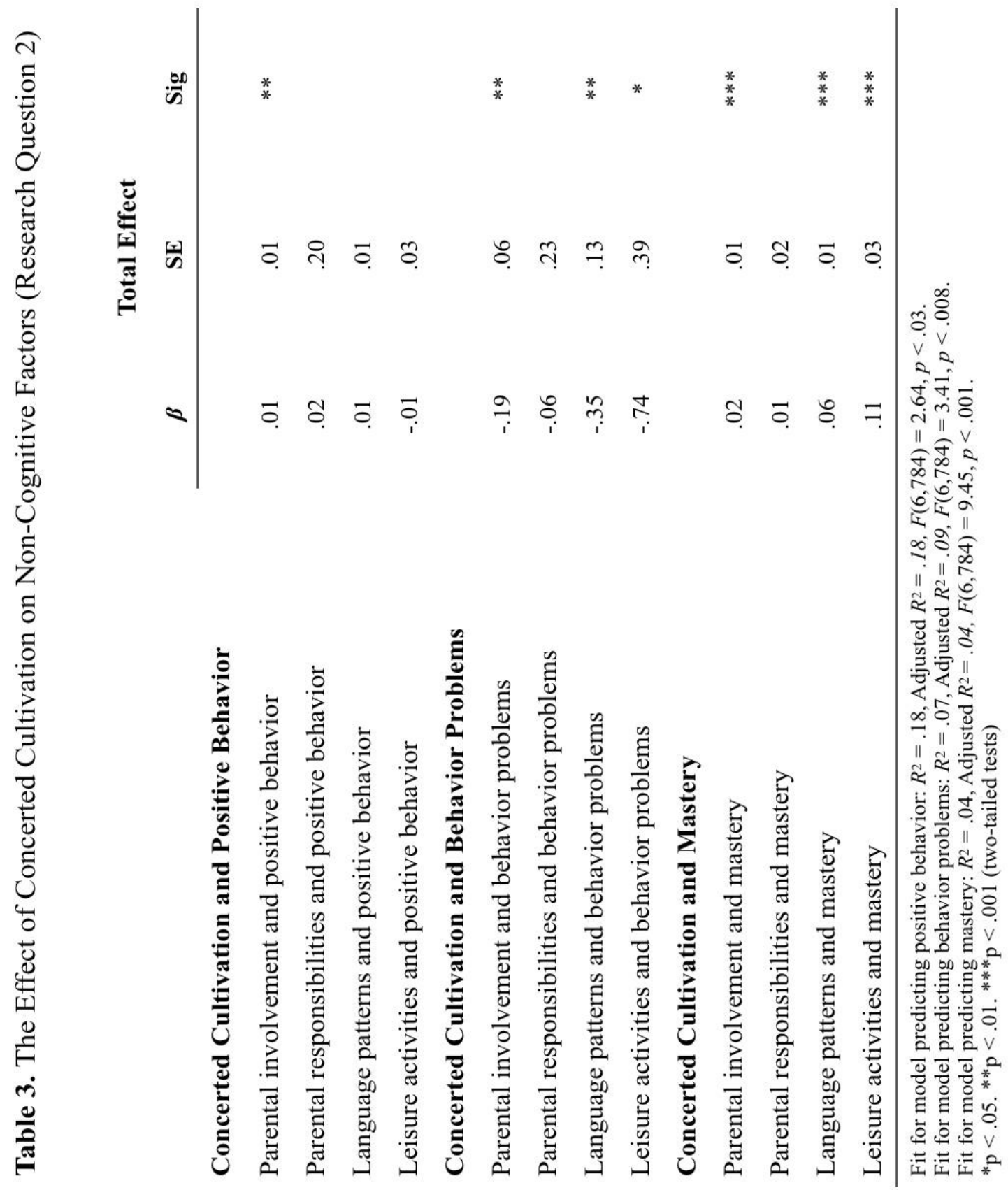


Concerted cultivation and positive behavior. The concerted cultivation model, comprised of scores connected to parental involvement with school, parental responsibilities, language patterns, and leisure activities, is positively and significantly associated with positive behavior $(F(6,784 ; p<.001)$. This is a relatively large association and corroborates the observations of Bodovski and Farkas (2008) and supports traditional status attainment theories, particularly aspects of the Wisconsin School status attainment model (Sewell and Hauser 1976).

Parental involvement is positively and significantly associated with positive behavior $(B=.01, z=3.15, p<.003)$. This finding confirms previous research demonstrating the positive association between parental involvement and children's behavioral outcomes in school (Hill \& Tyson 2009) and is consistent with Lareau's (2003) contention that parents practicing a concerted cultivation parenting approach scaffold the development of children's behaviors that are most facilitative of institutional success. However, parental responsibility is not significantly associated with positive behaviors $(B=.02, z=1.25 ; p<.79)$. Language patterns $(B=.01, z=1.33, p<.17)$ and leisure activities are also not significantly associated with positive behaviors $(B=-.01, z$ $=-.43, p<.97)$. The overall concerted cultivation model fit for positive behavior is $R^{2}=$ .18 .

Concerted cultivation and behavior problems. The concerted cultivation model, including variables for parental involvement with school, parental responsibilities, language patterns, and leisure activities, is negatively and significantly associated with behavior problems $(F(6,784)=6.23, p<.001)$. In addition to corroborating the observations of Bodovski and Farkas (2008) and supporting status attainment models 
(Sewell and Hauser 1976), this finding is consistent with recent research connecting concerted cultivation, and parental involvement in particular, to reductions in children's behavior problems (Kalil et al. 2014). Parental involvement is negatively and significantly associated with behavior problems $(B=-.19, z=-2.88, p<.005)$. This finding is consistent with a recent nationally representative longitudinal study of parental involvement that demonstrated a significant association between parental involvement and behavior problems (El Nokali et al. 2010). Parental responsibilities are not significantly associated with behavior problems $(B=-.06, z=-.83, p<.77)$. Indeed, no significant difference in behavior problems is observed between students with parental responsibilities scores of zero (baseline) and students with parental responsibilities scores of one $(p<.85)$, two $(p<.92)$, or three $(p<.47)$. However, both language patterns $(B=-$ $.35, z=-3.86, p<.007)$ and leisure activities $(B=-.74, z=-1.78, p<.05)$ are negatively and significantly associated with behavior problems. The overall concerted cultivation model fit for behavior problems is $R^{2}=.09$.

Concerted cultivation and mastery. The concerted cultivation model is positively and significantly associated with mastery $(F(6,784)=8.93 ; p<.001)$. This finding confirms Lareau's (2003) argument that a concerted cultivation parenting approach facilitates children's acquisition of a self-efficacious and mastery-oriented engagement within key institutions like schools (Lareau 2015; Bodivski and Farkas 2008). Moreover, this finding is consistent with recent research identifying parental socialization as a key mechanism towards children's development of mastery and confidence (Conger et al. 2009). Parental involvement is significantly associated with mastery $(B=.02, z=2.92, p$ $<.001)$. Holding all other independent variables in the model constant, for every unit 
increase in parental involvement the mean mastery score is estimated to increase 0.01 units (95\% CI: $0.001,0.028)$. Parental responsibilities are not significantly associated with mastery $(B=.01, z=.28 ; p<.93)$. No significant difference in mean mastery score is observed between students whose parents have parental responsibilities score of zero (baseline) and students with parental responsibilities scores of one $(p<.34)$, two $(p<$ $.62)$, or three $(p<.07)$. Language patterns are significantly associated with mastery $(B=$ $.06, z=4.82 ; p<.001)$. Holding all other independent variables constant, for every unit increase in language patterns the mean mastery score is estimated to increase 0.04 units (95\% CI: $0.02,0.07)$. Leisure activities are also significantly associated with mastery ( $B$ $=.11, z=6.25, p<.001)$. The overall concerted cultivation model fit for mastery is $R^{2}=$ .04 .

Consistent with recent observations (Heckman 2012; Farrington et al. 2012), the model shown in Table 4 provides support for my third hypothesis expecting a positive and significant relationship between non-cognitive factors and academic achievement. 


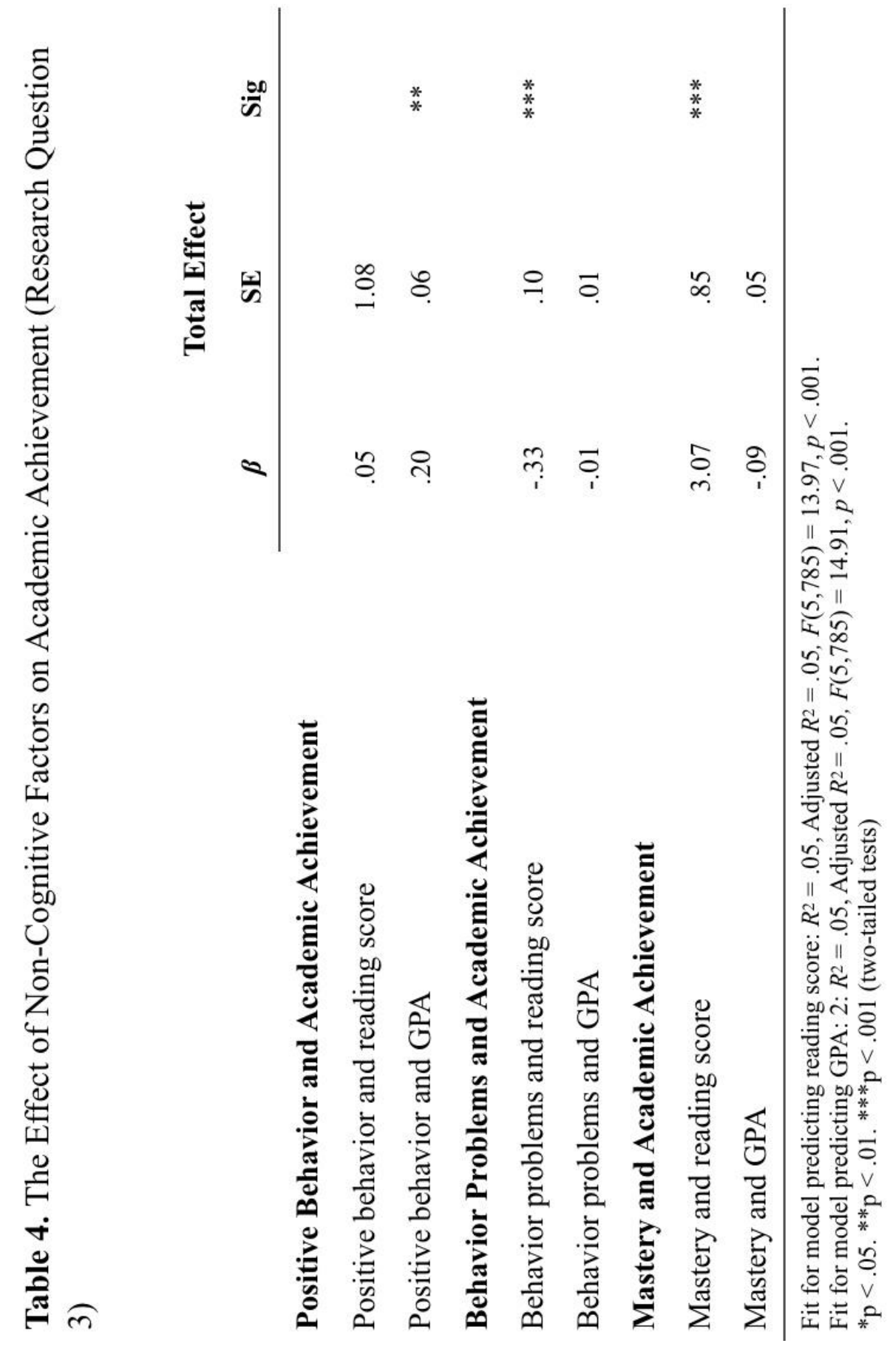


Positive behavior and academic achievement. As noted in Table 4, although positive behaviors are not significantly related to reading score $(B=.05, z=.05, p<.95)$, they are positively and significantly associated with high school GPA, with a standardized path coefficient of $.20(z=3.04, p<.002)$. This is a moderate coefficient that supports a recent meta-analytic study demonstrating the positive effect of socioemotional interventions on academic achievement (Durlak et al. 2011). Previous research has demonstrated that positive social skills are determinative of future academic achievement (Wentzel 1991), with Malecki \& Elliott (2002) reporting that positive behaviors commonly function as "academic enablers in school environments" (18). Given the non-significant relationship between positive behavior and reading score, it appears that positive social behaviors may have greater impact on more comprehensive academic performance measures like GPA that assess a broader range of academic behaviors, attitudes, and strategies than standardized tests.

Behavior problems and academic achievement. As shown in Table 4, the association between behavior problems and reading score is negative and significant ( $B=$ $-.33, z=-3.28, p<.001)$, while the relationship between behavior problems and high school GPA is negative and non-significant with a standardized path coefficient of -..01 ( $z$ $=-1.74, p<0.08)$. The inverse relationship between behavior problems and academic achievement is consistent with research documenting a significant relationship between maladaptive behavior in school and academic performance (Liu 2016).

Mastery and academic achievement. There are contrasting findings in the associations between mastery and academic achievement. The direct pathway between mastery and reading score, as demonstrated in Table 4 , is positive and significant $(B=$ 
$2.18, z=3.59, p<.001)$. However, the relationship between mastery and high school GPA is negative and non-significant, with a path coefficient of $-.09(z=-1.77, p<.07)$. This is an unexpected finding, as mastery was hypothesized to have a positive association with both measures of academic achievement. Although mastery is typically positively associated with psychological health and wellbeing (Conger et al. 2009), the relationships connecting interpersonal skills to academic achievement is less clear in the literature. For example, Bodovksi and Farkas (2008) report a negative association between higher interpersonal skills and test scores.

The non-cognitive factors model, comprised of positive behaviors, behavior problems, and mastery, is positively and significantly associated with both measures of academic achievement, standardized reading score $(F(4,786)=33.50, p<.001)$ and high school GPA $(F(5,785)=17.70, p<.001)$. This finding indicates that non-cognitive factors in middle school constitute a direct and significant pathway to academic performance in middle school and then years later in high school as captured through GPA. This finding is noteworthy given that there are at least seven years between the age at which respondent's reading was tested and their GPA earned, spanning different developmental points in student's lives. Research suggests that non-cognitive factors are typically stratified by family social background status early in life (Cunha \& Heckman 2009), and that these non-cognitive factors in turn positively affect learning throughout a child's years in school. The combined effect of these intersecting trends amounts to an ever-widening social background achievement gap by sorting students into diverging developmental trajectories, as children from middle and upper-class families are better 
poised to flourish by virtue of the fact that their non-cognitive factors make them more institutionally adaptive (Liu 2016).

The central objective of this study is to merge relatively independent areas of research related to the impact of concerted cultivation and non-cognitive factors on academic achievement, hypothesizing that non-cognitive factors mediate the pathway connecting concerted cultivation and academic achievement. Perhaps the socialization practices embedded within the concerted cultivation parenting approach manifest in children as non-cognitive factors that amount to an interpersonal skills pathway that leads to more adaptive functioning in institutions like schools, thereby compounding a previously existing social class-related advantage. I address this by estimating the indirect effects of concerted cultivation, as measured by parental involvement, parental responsibilities, language patterns, and leisure activities, on achievement, as measured by reading score and high school GPA. I focus on those indirect effects that are transmitted though non-cognitive factors, as measured by positive behaviors, negative behaviors, and mastery. As modeled in Figure 1, there are three indirect paths through which the concerted cultivation variables influence the two academic achievement variables: (1) concerted cultivation - positive behaviors - reading score and GPA; (2) concerted cultivation - behavior problems - reading score and GPA; and (3) concerted cultivation mastery - reading score and GPA. Table 5 reports the total and indirect effects of positive behavior. 


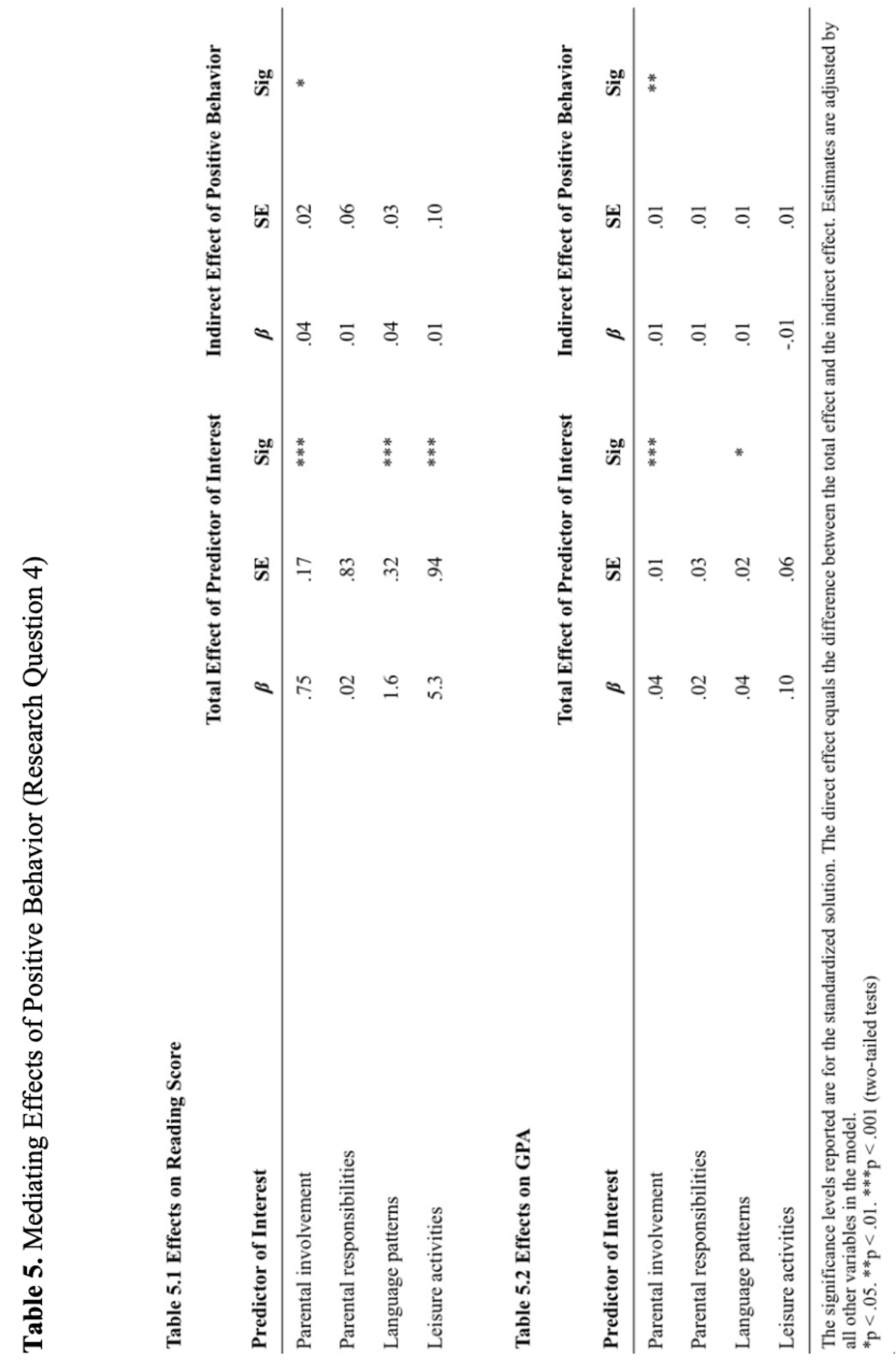


As noted in Table 5, there is a significant indirect effect of parental involvement on reading score that is mediated by behavior problems $(B=.04, z=1.88, p<.03)$. Similarly, there is a significant, though relatively small, indirect effect of parental involvement on high school GPA that is mediated by behavior problems $(B=-.01, z=$ $1.25, p<.009)$. Given the seven-year assessment gap between the two academic achievement measures, reading score and GPA, this finding links engagement from parents with prosocial behaviors and two separate achievement measures from middle school to high school. Table 6 reports the total and indirect effects of behavior problems. 


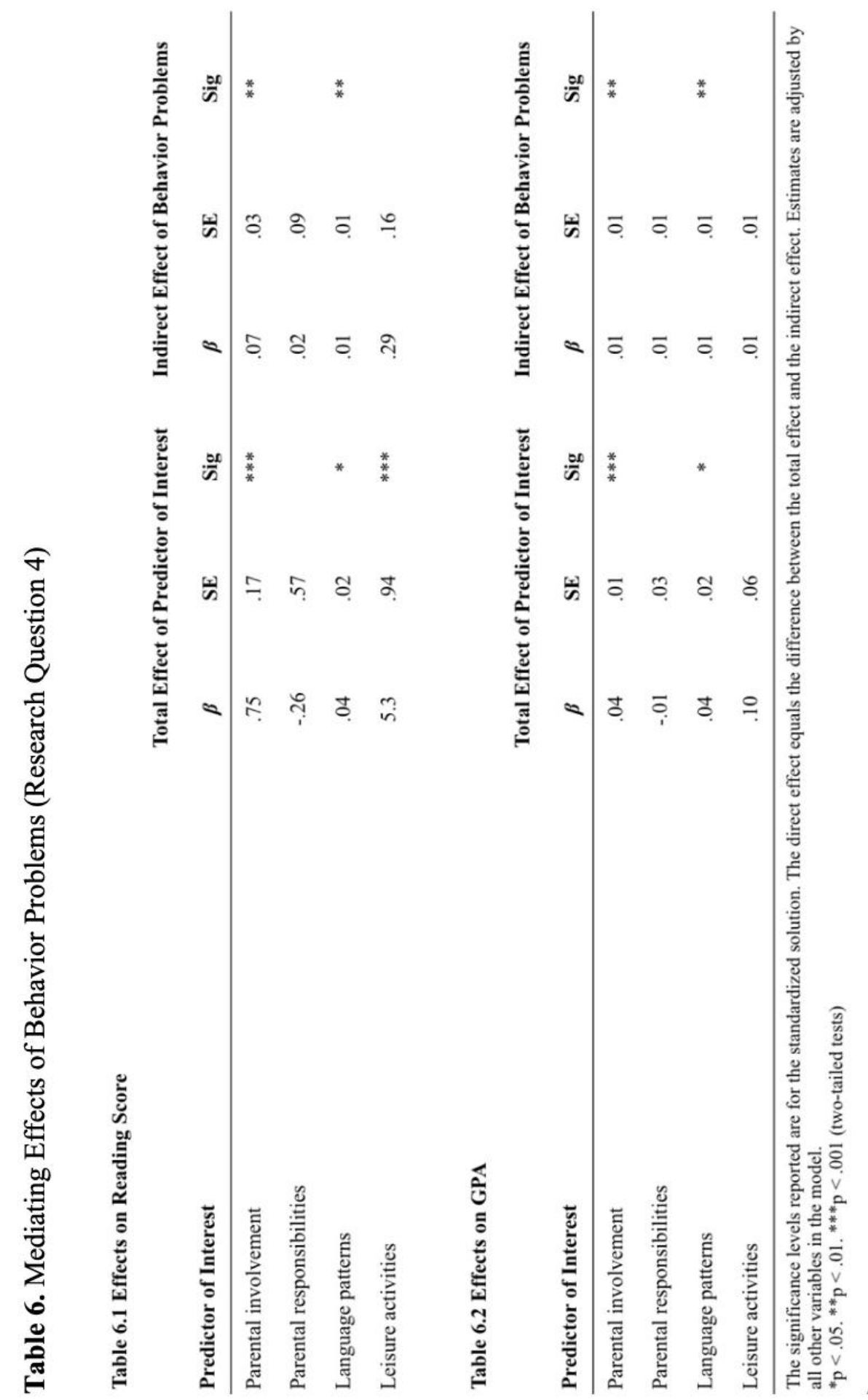


As noted in Table 6 , there are significant effects of both parental involvement ( $B$ $=.07, z=2.32, p<.01)$ and language patterns $(B=.01, z=1.41, p<.01)$ on the first academic achievement measure, reading score, that is mediated by behavior problems. These two concerted cultivation domains, parental involvement $(B=.01, z=1.16, p<$ $.01)$ and language patterns $(B=.01, z=1.34, p<.01)$, also have significant effects on the second academic achievement measure, high school GPA, that is mediated by behavior problems. These findings confirm Lareau's (2003) model connecting concerted involvement from parents to child behavior, in this case lower behavior problem scores, that is more likely to be institutionally rewarded. Moreover, these results extend Bodovski and Farkas's (2008) finding on concerted cultivation and behavior problems by establishing behavior problems as a mediating path connecting two domains of concerted cultivation with academic achievement. Table 7 reports the total and indirect effects of mastery. 


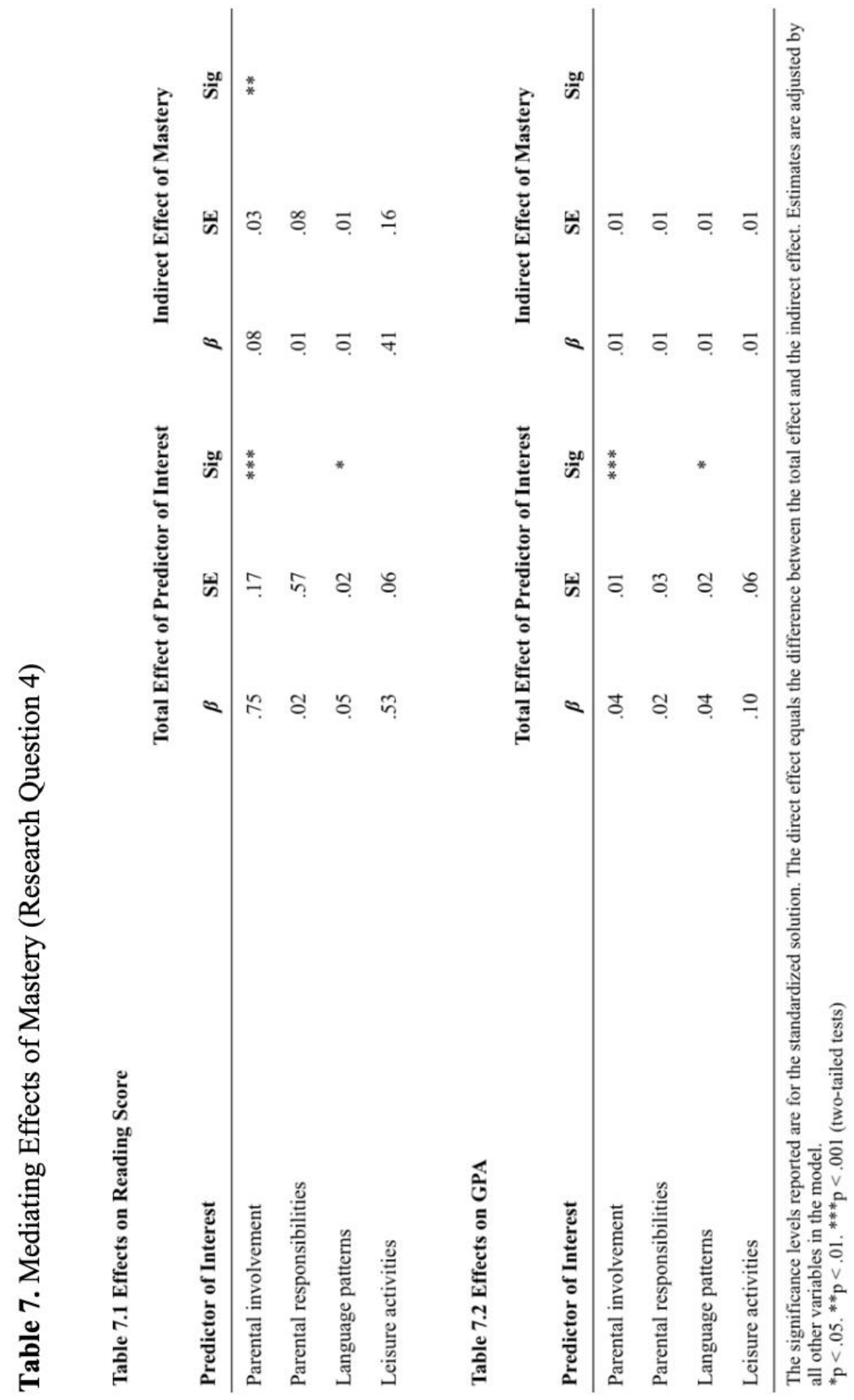


The path results for the third non-cognitive factor, mastery, indicate a significant indirect effect of parental involvement on reading score that is mediated by mastery $(B=$ $.08, z=2.70, p<.004)$. Although this is a relatively small effect, it adds to previous research documenting the expansive range of ways through which parental involvement manifests in the behaviors and performance of children in academic settings (Lareau 2003; Bodivski and Farkas 2008; Cheadle 2008; Smith 2006).

Overall, the results support the central hypothesis of the study positing that noncognitive factors mediates the relationship between concerted cultivation and academic achievement. Each of the non-cognitive variables assessed, positive behavior, behavior problems, and mastery, significantly mediate the effect concerted cultivation domains have on academic achievement. Specifically, positive behavior significantly mediates the relationship between parental involvement and both reading score and high school GPA; behavior problems significantly mediates the relationship between parental involvement and reading score and language patterns and reading score, and parental involvement and high school GPA and language patterns and high school GPA; and mastery significantly mediates the relationship between parental involvement and reading score. 


\section{Chapter 5: Discussion}

I have proposed a specified path model related to the reproduction of social class inequality among students, using estimates from a longitudinal and nationally representative dataset of children at three measurement points (1997, 2002, and 2009). I addressed the following research questions: To what degree are mother's education and educational expectations associated with concerted cultivation? To what degree is parenting, specifically concerted cultivation, associated with non-cognitive factors in school? To what degree are non-cognitive factors associated with academic achievement? To what degree do non-cognitive factors mediate the relationship between concerted cultivation and academic achievement?

In order to build on previous quantitative research assessing the impact of concerted cultivation, I measured concerted cultivation using the summed indicators established through confirmatory factor analysis by Carolan and Wasserman (2015) in the four areas identified as constitutive of concerted cultivation by Lareau (2003): parental involvement with school, parental responsibilities, language patterns, and leisure activities. Whereas Carolan and Wasserman (2015) focused on the mediating effects of parental expectations and concerted cultivation on social background and academic achievement, I focused on the mediating effects of non-cognitive factors that stand between concerted cultivation and academic achievement. I used three measures assessing non-cognitive factors: The Positive Behavior Scale (Polit 1998), the Behavior Problem Index (Peterson and Zill 1986), and the Pearlin Mastery Scale (Pearlin and Schooler 1978). I used two measures of academic achievement, a standardized test assessing reading comprehension in middle school, and high school GPA. Using these 
two measures of academic achievement provided the opportunity to assess achievement at two different developmental time points for students, as well as to capture how noncognitive factors impact academic performance through teacher assessment of student behavior on GPA. Moreover, although to some degree both standardized tests and GPA impact academic outcomes and transitions into the labor market, GPA appears to function as a more robust predictor of academic and labor market outcomes than standardized achievement measures (Betts and Morell 1999) because it captures elements of both social and academic fitness.

This study was deeply informed by Bourdieu (1976) and Lareau's (2003) work on cultural capital and the cultural logics of parenting, and how schools often function as the vehicle whereby those in the middle and upper-classes reproduce their advantage in capitalist economies. Whereas the correspondence theory of Bowles and Gintis (1976) proposed a similar structural model of capitalist labor market and academic institution symbiosis, Bourdieu supplements the structural approach with a focus on cultural mechanisms, providing a dynamic model of social inequality, anchored by the notion of cultural capital, which facilitates capturing moments of social reproduction. A goal of this study was to capture moments in the home with parents, at school interacting with others and with one's own sense of mastery in that context, and in the formal evaluative domain of tests and grades, with the expectation that these collective moments would braid together and clarify pathways through which parents are actors on their children's school trajectory.

Mother's Education and Concerted Cultivation 
The significant relationship between mother's education, educational expectations, and concerted cultivation supports the theory that class-based reproduction begins with children's social background, as measured by mother's education and educational expectations in this study. According to Bourdieu's cultural capital theory, parents transmit advantages or disadvantages to their children through their class-based cultural heritage. Class distinctions for Bourdieu were "mediated by both aspirations and expectations and cultural style and knowledge into differential educational performance and attainment" (Schwartz 1997:199), and the significant relationship between mother's education and a class-based parenting approach appears to be an early and crucial part of the transmission of advantage or disadvantage for the students in this study.

\section{Concerted Cultivation and Non-Cognitive Factors}

In support of Lareau's (2003) theory that a concerted cultivation parenting approach socializes children in ways that lead to behavioral and social readiness for institutions such as schools, the results demonstrate that concerted cultivation is directly related to non-cognitive factors identified as pivotal to academic and labor market achievement (Farrington et al. 2012; Heckman et al. 2010). Carolan and Wasserman (2015) theorize that although concerted cultivation was not significantly associated with academic achievement in their study, "perhaps concerted cultivation functions more as a deeply embedded sense of entitlement that has substantial non-cognitive value" (180). Results from this study provide validation for this theory, as the concerted cultivation model is significantly associated with all three non-cognitive factors measured five years after the concerted cultivation data was collected. More specifically, a path analysis on a national sample of children suggests that higher-SES parents cultivate, through their 
parenting and teaching, behaviors and mastery-related attitudes in children that relate to positive academic achievement outcomes.

These findings extend the work of Bourdieu, who observed that student academic performance related strongly to the cultural background of their parents. According to Bourdieu (1979), class-based differences in cultural capital, including both cultural knowledge and style, perpetuate inequality via the educational system (Swartz 1997). The concept of habitus was central for Bourdieu, as it refers to a set of relatively stable ideas about one's prospects for social mobility and an awareness of the rules and norms of society. Bourdieu referred to these class-based ideas as dispositions that compelled people to behave in ways that "reproduce the prevailing structure of life chances and status distinctions" (Swartz 1997:197). Invoking the work of Bourdieu on habitus, Lareau theorized that concerted cultivation parenting nurtures the behaviors and attitudes of children in a manner that is congruent with academic achievement. She notes, "taken together the elements discussed in this book do constitute a set of dispositions that children learn, or habitus" (2003:276).

Although the concerted cultivation model was significantly related to each of the non-cognitive factor domains, only one of the four concerted cultivation domains, parental involvement, was significantly associated with positive behaviors, behavior problems, and mastery. These findings build on recent research documenting the importance of parental involvement in children's outcomes, particularly involvement in early education as this helps shape academic motivation and attitudes (Wang and Eccles 2012; Dweck 2010; Lareau 1987). In a review of the literature on the impact of families and school motivation, Grolnick et al. (2009) report that parental involvement is 
associated with student reports of increased competence, control, and positive attitude and motivation toward academics, even when parents are unable to provide specific academic content assistance. The significant association between parental involvement and positive behaviors, behavior problems, and mastery in this study validate recent findings. Wang and Eccles (2012) report that the majority of middle-school adolescents are significantly influenced by parents on measures of student school engagement, and their perceptions of support, both at home and in the schools, positively influence school engagement behaviors and motivation, despite temptations from their peers to misbehave outside of class. A recent longitudinal study using a nationally representative sample of students found that although parental involvement did not significantly predict academic achievement, it did predict reductions in behavior problems (El Nokali et al. 2010).

It may be that targeted parental involvement in school through concerted cultivation early in life creates a default standard of expectations and achievement to which children assume they will subsequently be held accountable and for which they believe they are equipped and even destined. For example, Lareau (2003) reports that families employing a concerted cultivation parenting approach were infrequently intimidated by institutional surroundings and expected these institutions to be highly responsive to their needs and involvement. It is possible that the findings related to parental involvement in this study were assessing elements of institutional entitlement, as parents practicing a concerted cultivation style expect schools to facilitate academic success and will intervene if they believe schools are not performing. It could also be that these parents intervene and initiate engagement with schools early in children's academic 
life, and in so doing provide a social learning model for their children (Bandura 1977; Bodivski and Farkas 2008).

\section{Non-Cognitive Factors and Academic Achievement}

According to Lareau (2003), depending largely upon parents' beliefs about what is possible to achieve and what feels most natural to them, they will organize activities for their children, engage verbally in more or less extensive and nuanced patterns, and report different levels of responsibility and become involved in school presumably related to their ideas about the process of attaining what is socially achievable. The findings of this study build on previous research that confirms how parental dispositions, preferences, and perceptions of opportunities impact engagement with children in a way that creates a child's habitus (Bodivski and Farkas 2008), and it extends this area of literature by linking a child's habitus to a set of non-cognitive factors that influence academic achievement.

I further examined how potential advantages connected with middle and upperclass parenting that provide cultural institutional readiness for school may be transmitted into academic performance by assessing the extent to which non-cognitive factors are associated with academic achievement. My models indicate that non-cognitive factors in middle school constitute a direct and significant pathway to academic performance in both middle school (standardized reading score) and high school (GPA), with the relationship between non-cognitive factors and standardized reading score stronger than the relationship between non-cognitive factors and GPA.

This finding may be accounted for in part by how teacher bias may shape judgements about grades and behaviors for different students. Entwisle et al. (2001) 
report that children from more impoverished backgrounds were not graded relative to their progress and advancement during a school year, but rather on where they started, even in instances when the more impoverished students made gains on standardized tests at the same rates as students from more affluent backgrounds. Accordingly, parents from more impoverished backgrounds were given the indication that their children had made little academic progress, potentially impacting subsequent levels of parental involvement. Entwisle et al. (2001) also report that the relative level of grades impacted how teachers viewed their students. For example, when asked to predict how students would perform in the succeeding year following first grade, the teachers' forecasts closely related to the overall grading patterns of the school. Teachers in high economic status schools expected their students to get more A and B grades than C's or below, while teachers in low economic status schools expected the majority of their students to get $\mathrm{C}$ grades or below.

Teacher ratings of classroom behavior also corresponded to grades. In a school with 11 percent of children on a meal plan, teachers assessed students much higher in both classroom participation and general interest than teachers in a school with 90 percent of students on a meal plan (Entwisle et all. 2001). Whereas schools with high percentages of children on meal plans report at least some children at the lowest class participation levels, in more affluent schools no children were similarly rated at the lowest class participation levels.

Entwisle et al. (2001) summarize the findings of their analysis as poor children being likely to be assigned poor grades, expected by their teachers to subsequently earn similarly poor grades, and assessed as lacking in essential learning-facilitative non- 
cognitive factors, despite these children learning at equivalent rates during the same school year and in the same school districts as their more affluent peers.

Variations in levels of parental involvement according to social background may impact teacher perceptions of student academic performance. Lareau (1987) reports that differences in social, cultural, and economic resources between working and middle-class parents help to explain class-based response differences to teacher requests to participate in school. For example, working-class parents reported feeling reluctant to help with their children's reading and school work due to beliefs that their skills were not adequate to intervene. Regrettably, teachers may be interpreting this hesitancy of working-class parents to become more involved as disinterest rather than a sense of inadequacy or low sense of agency, and this potential misinterpretation of parental disengagement may in turn lead to the type of class-based teacher grading bias reported by Entwisle et al. (2001).

In this study, given that there are at least seven years between the two academic achievement measures, the findings confirm the important role that non-cognitive factors play in academic achievement and indicate that the impact of non-cognitive factors may accumulate as students develop and navigate social institutions like schools (Liu 2016). Research suggests that non-cognitive factors are typically stratified by family social background status early in life (Cunha \& Heckman 2009), assessed as socially and culturally appropriate by teachers and other institutional authority figures (Lareau 2003; 2015), and that these non-cognitive factors in turn positively affect learning throughout a child's years in school.

The Mediating Influence of Non-Cognitive Factors 
The path model results in this study provide additional validation of cultural capital reproduction theories. Specifically, findings from this study indicate that concerted cultivated parenting scaffolds the development of behaviors and attitudes that connect with academic achievement in both middle school and high school. Bourdieu's notion of habitus refers to behaviors that produce a system of life opportunities and class and status distinctions, so the behaviors associated with each of the measures used in this study, positive behaviors, behavior problems, and sense of mastery, appear to connect with his initial conceptualization of habitus.

Specifically, positive behavior significantly mediates the relationship between parental involvement and both reading score and high school GPA. This finding is perhaps unsurprising given recent research connecting prosocial behaviors and academic achievement (Farrington et al. 2012) and Bourdieu's contention that habitus is the product of early socialization experiences internalizing external structures (Swartz 1997), whereby parent involvement with their children and schools becomes internalized by children in a way that primes them to employ those interpersonal styles, such as behaving positively, that are most suited or adapted for academic success.

Behavior problems was a strong mediator in this study, connecting the parental involvement and language pattern concerted cultivation variables to both measures of academic achievement. Both of these concerted cultivation domains, parental involvement and language patterns, are constitutive of parental engagement with children and the learning process in the context of schools (e.g., parental discussions with teachers, parental discussions with their child about their interests, studies, and the school). The pathways identified in this study connecting these two concerted cultivation 
domains with lower behavior problem scores and higher academic achievement levels give additional support to the notion of middle-class parent's ability to find their way inside a closed classroom (Hassrick and Schneider 2009). As Lareau observed (2003), middle-class parents obtained highly specific information about what was happening in classrooms and at school through social connections with school administrators, teachers, and parents, enabling them to create academic preparatory experiences in the home that tightly corresponded to activities in school. For example, in a study assessing class-based parent surveillance behaviors in schools, Hassrick and Schneider (2009) report that middle and upper-class "monitoring parents" observed and evaluated how teachers interacted with their children and also how these teachers managed misbehaving children and the ways this compromised the learning climate. Moreover, these parents assessed the institutional discipline policies connected with teaching and the learning climate, and used surveillance tactics to influence teacher implementation of disciplinary and academic policies in the classroom. Accordingly, it makes sense that the mothers in my study with higher education levels were more likely to become involved and even intervene in their child's schooling, and that these parental involvement and intervening strategies would carve a subsequent pathway to lower behavior problem scores and higher academic achievement scores.

Mastery also significantly mediates the relationship between parental involvement and reading scores. As with the other two non-cognitive factors, positive behaviors and behavior problems, middle-class parents were more likely to engage with their children in ways that increase the likelihood of children reporting higher levels of institutional readiness in the form of mastery. This finding, like the others related to the non-cognitive 
factors measured in this study, builds on previously related findings. Hassrick and Schneider (2009) report that middle-class parents in their study not only carefully monitored the academic experiences of their children, they also were more likely to intervene and report concerns about how their children's self-esteem was impacted by classroom events.

Each of the non-cognitive variables assessed, positive behavior, behavior problems, and mastery, significantly mediate the effect concerted cultivation domains have on academic achievement, which builds on a growing body of research documenting the impactful role non-cognitive factors play in the stratification process. Implications for Administrators and Teachers

Despite indications that the academic system in the U.S. appears to be inextricably connected with the fluctuations and structural inequalities of the capitalist economic system (Bowles and Gintis 1976; Anyon 2011), administrators and teachers are often identified as the problem. Framing education too narrowly as the performance of administrators and teachers not only runs the risk of scapegoating those in classrooms working with diminishing resources and support, it also obscures the larger system of actors. These actors determine funding to the academic system and school districts, compose and implement curriculums, and hire and evaluate teachers.

A central implication of my study for administrators and teachers is the need for greater resources and support for the crucial developmental role teachers play in shaping children, particularly in light of the findings in this study indicating that teachers have an opportunity to impact those non-cognitive factors that appear to be determinative of student success. 
Supporting high-quality teaching has been primary to the development of highachieving educational systems. An analysis of twenty-five of the world's educational systems, including the ten top achieving systems, indicated that investments in teachers were the central factor improving student outcomes. The ten highest-achieving systems specifically identified intentional recruitment, preparation and development, and systematic institutional support as critical. These educational systems provide thorough preparation for teaching, pay teachers advantageously compared to comparable professions, and provide extensive professional development learning time. Additionally, "they also distribute well-trained teachers to all students - rather than allowing some to be taught by untrained novices - by offering equitable salaries, sometimes adding incentives for harder-to-staff locations" (Darling-Hammond 2012:27).

In addition to providing adequate and equal funding, policy changes in the U.S. that contribute to the reduction of socio-economic inequality through increasing access to qualified teachers should increase investments in teacher education programs, including subsidizing the cost and providing stipends; paying salaries that are equitable across all schools and competitive with other occupations; and supporting ongoing teacher learning opportunities and mentoring, particularly in areas like socio-emotional learning that relate to those non-cognitive behaviors most facilitative of school performance.

In contrast to the current U.S. system, in which teachers accrue debt throughout their training and are then paid at levels below occupations with related training and educational requirements, countries with high-achieving educational systems have wisely invested in teachers. For example, Finland, Canada, Singapore, and South Korea recruit highly competitive candidates, subsidize their education, pay them while they are 
learning, and then compensate them well throughout their professional careers (DarlingHammond 2012). In these countries, teacher pay tends to correspond with the compensation for engineers, and working conditions are characterized as supportive, collaborative, and participatory when it comes to institutional decisions at all levels.

In the U.S., the data suggests that new teachers are most likely to be least effective, and likely to be located in low-income schools where students need the most help learning essential non-cognitive academic behaviors and attitudes. These trends, combined with data indicating that low-income schools have the lowest proportion of experienced teachers mentoring new teachers, result in steep instructional disadvantages for students in low-income schools (Boyd et al. 2011).

\section{Limitations and Significance of the Study}

The findings of this study should be considered in light of several limitations. The use of the term non-cognitive can be conceptually confusing. Attempting to distinguish non-cognitive factors from cognition is challenging given that the majority of human behavior involves cognitive processes, such that behavioral and cognitive processes appear to be mutually informing (Borghans et al. 2008). Nevertheless, as Farrington et al. (2012) note in their review of the literature on non-cognitive factors and academic achievement, "the word non-cognitive is already deeply embedded in educational policy circles, in the economics literature, and in broader discussions of student achievement" (2).

There is also a lack of consensus in the literature on what specific behaviors correspond with certain non-cognitive factors, and the degree to which measures assessing a general sense of mastery, for example, may correspond with a more specific 
sense of mastery in an academic context. The assessment of mastery used in this study provides a general measure of sense of mastery, but the degree to which this general sense of mastery may or may not correspond to the literature on academic mastery attitudes relevant to academic performance is unknown.

The impact of social behaviors on academic achievement is somewhat unclear given the large proportion of correlational studies in the literature and variations in definitions of non-cognitive factors and soft skills. An often-cited definition of social behaviors is "socially acceptable learned behaviors that enable a person to interact effectively with others and to avoid socially unacceptable responses" (Gresham and Elliott 1990:1). The Collaborative for Academic, Social, and Emotional Learning (CASEL) identifies five core competencies, including self-management, self-awareness, social awareness, relationship skills, and responsible decision-making. A limitation of this study is the potential degree to which parents might have had different ideas about what constitutes positive behavior for their children; for example, compliant versus questioning behavior could have been assessed differently by parents, particularly given the decontextualized nature of the questions. While the two non-cognitive measures used in this study to assess positive behavior and behavior problems do assess behaviors that enable children to interact effectively, avoid socially unacceptable responses, and practice social awareness and relationship skills, neither measure was constructed specifically for the academic context. Thus, as with the measure used in this study for mastery, attempts to interpret the decontextualized student non-cognitive behavior scores in the context of an academic setting must be done so cautiously. 
One of the dependent variables, high school GPA, depends on a retrospective selfreport. However, the inclusion of a measure that incorporates teacher ratings and grades on work students complete such as GPA, is an important component for assessing both concerted cultivation and non-cognitive factors. In addition to assessing content knowledge, grades capture the extent to which students employ a variety of behaviors that facilitate success throughout the lifespan, such as social and academic problemsolving skills, work habits, and metacognitive strategies (Farrington et al. 2012). Additionally, two of the measures for non-cognitive factors, positive behaviors and behavior problems, rely on parent reports, so the extent to which parents provided biased reports is unknown. Although this study assessed a relatively small number of noncognitive factors among a range of potentially significant mediating non-cognitive factors, the sample size and use of a path analysis to clarify both the direct and indirect pathways connecting non-cognitive factors to parenting and academic achievement make this a meaningful contribution to the literature.

There is a need for future research on other presumably salient non-cognitive factors mediating parenting style and academic achievement, including conscientiousness and more nuanced measures of academic behaviors and attitudes. As noted in the results section, the models accounted for relatively small amounts of variance in the academic achievement measures. Although the objective was to identify reliable mediating relationships between the variables, and not necessarily prediction, the relatively small amount of variance accounted for by the models in this study nevertheless point to many unmeasured factors not included in this analysis. 
The results of the study provide support for cultural reproduction theory by documenting the capacity of parents to confer advantages to children based on class location and the related cultural logic of their parenting approach. Each of the noncognitive variables assessed, positive behavior, behavior problems, and mastery, significantly mediate the effect concerted cultivation domains have on academic achievement. Thus, as was the case with the Wisconsin model, variability in academic achievement is in part accounted for by "social-psychological" processes (e.g., positive behaviors, behavior problems, and mastery) that mediate the impact of parenting approach on academic performance.

An additional strength of this study is the use of an empirical measure that has operationalized Lareau's concerted cultivation construct with nationally representative quantitative data, and the ability to assess concerted cultivation across time, from early to late adolescence, given the design of the PSID, CDS, and TA Study. Results from this study indicate that non-cognitive factors assessed in early adolescence mediate the relationship between concerted cultivation assessed in childhood and a proximal achievement measure (standardized reading score in early adolescence) and distal achievement measure (high school GPA in late adolescence). Although parenting strategies and resources presumably change over time as children age, the impact of early (e.g., pre-school) class-based family experiences confer a compounding advantage. A concerted cultivation parenting approach when a child is young may hasten the development of institutionally prime non-cognitive skills, which may positively impact standardized test-taking ability in early adolescence, which may in turn positively contribute to general academic achievement in high school. 
By clarifying the mediating role of select non-cognitive factors, this study contributes to growing research that seeks to better understand the ways through which parents are actors on their children's academic trajectory. Research investigating how concerted cultivation and other class-based parenting approaches manifest non-cognitive skills and academic socialization advantages using mixed qualitative and quantitative approaches deserves future attention. Additionally, although there is a growing body of literature indicating the developmental processes associated with non-cognitive factors, future research that identifies school-based structural elements like funding, school climate, and teaching strategies is needed. Additional research is also needed to clarify the specific strategies that can be used to integrate research on non-cognitive factors in the classroom, along with continuing to develop non-cognitive measures that are contextually-specific to academic performance settings.

Disentangling the impact of non-cognitive factors on labor market success from the impact of academic achievement on labor market success is a theoretical and empirical task in progress. Although a considerable amount of literature has documented the impact of non-cognitive factors on labor market outcomes (Farkas 2003), those who are able to consistently deploy non-cognitive behaviors most adaptive to labor market success are often more likely to have obtained academic credentials, a dynamic feedback loop of sorts which supports elements of Bowles and Gintis' (1976) correspondence theory. The hegemonic culture and related ideologies in academic institutions, according to Anyon (2011), "saturate students and teachers alike" (34), such that "institutions of cultural preservation and distribution like schools create and recreate forms of 
consciousness that enable social control to be maintained without the necessity of dominant groups having to resort to overt mechanisms of domination" (Apple 3:1979).

It appears clear that children neither begin nor end their academic journey on a level playing field. However, despite this reality, much policy in the U.S. appears to suggest that schools are the place where inequalities are to be eliminated; schools are the institutions within which those social, economic, and familial circumstances initially shaping the imbalance are somehow corrected. This is an untenable proposition, not only due to the improbability of the educational system somehow transforming the social inequalities of which it is merely an outgrowth, but because the educational system itself has long structured inequality within its system by advantaging middle and upper-class cultural norms and behaviors.

Despite the recurring belief that “...public schooling remains our most hopeful site for disrupting inequality and injustice" (Oakes 2015:8), there seems to be a risk of conducting research and developing policies targeted perhaps too narrowly at educational inequality, and not the contextual socio-economic features of which educational inequality is a symptom (Bowles and Gintis 2011). Future research related to social reproduction in schools and the transmission of cultural advantages must continue to look across the social structure, consistently anchoring our analyses within those social, economic, and political mechanisms, such as the access to income and resources, from which educational inequality is born and fed. 

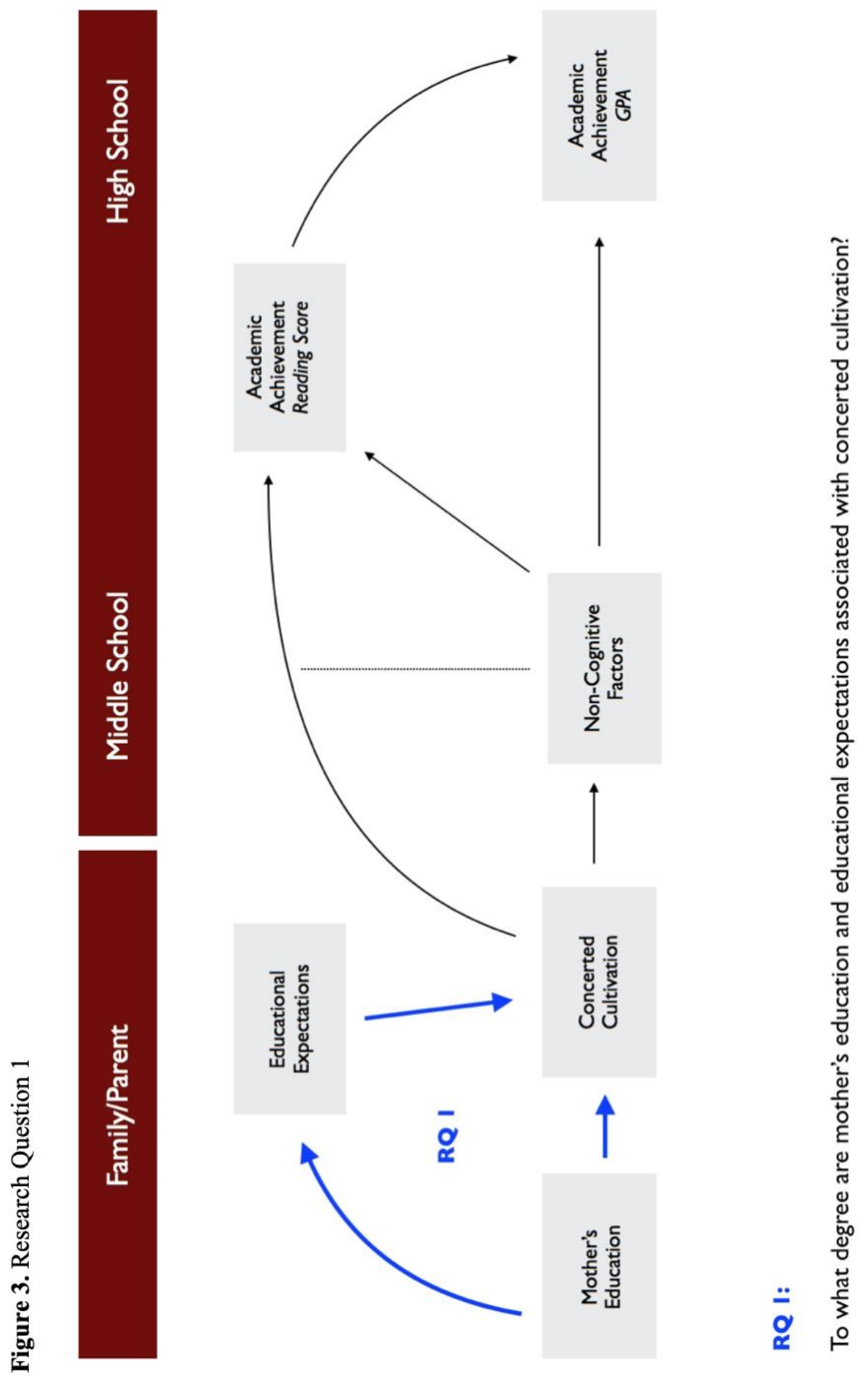


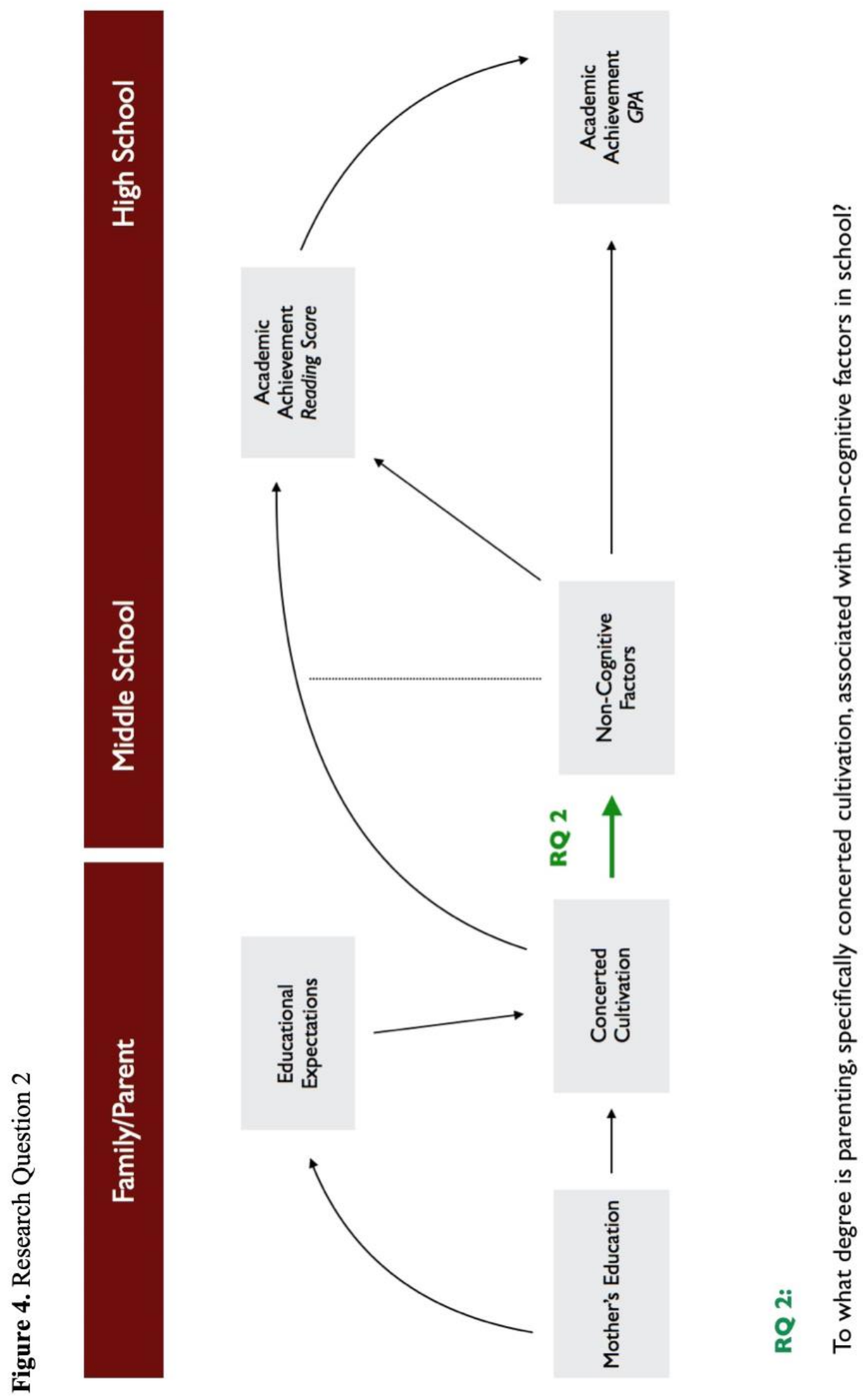



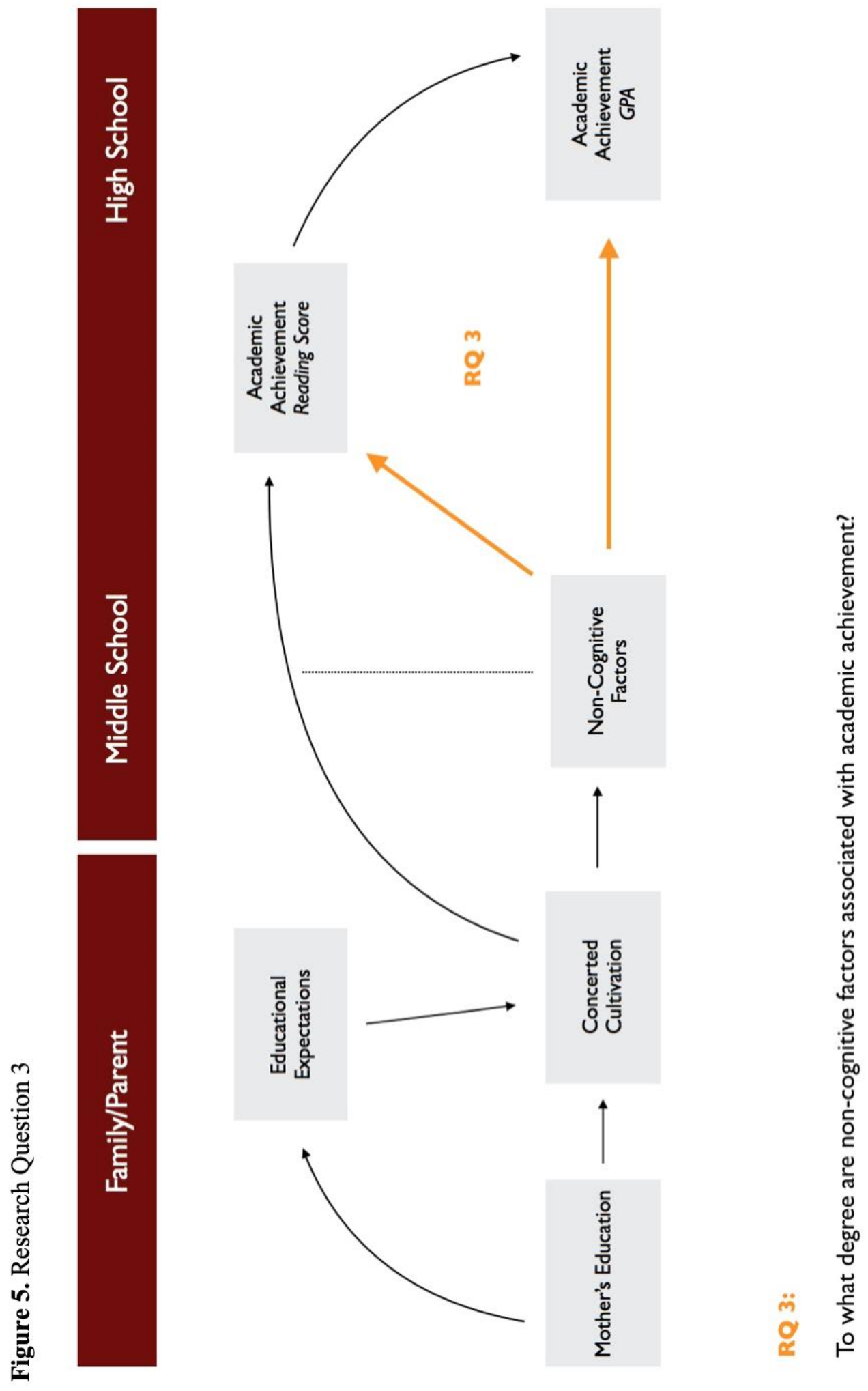


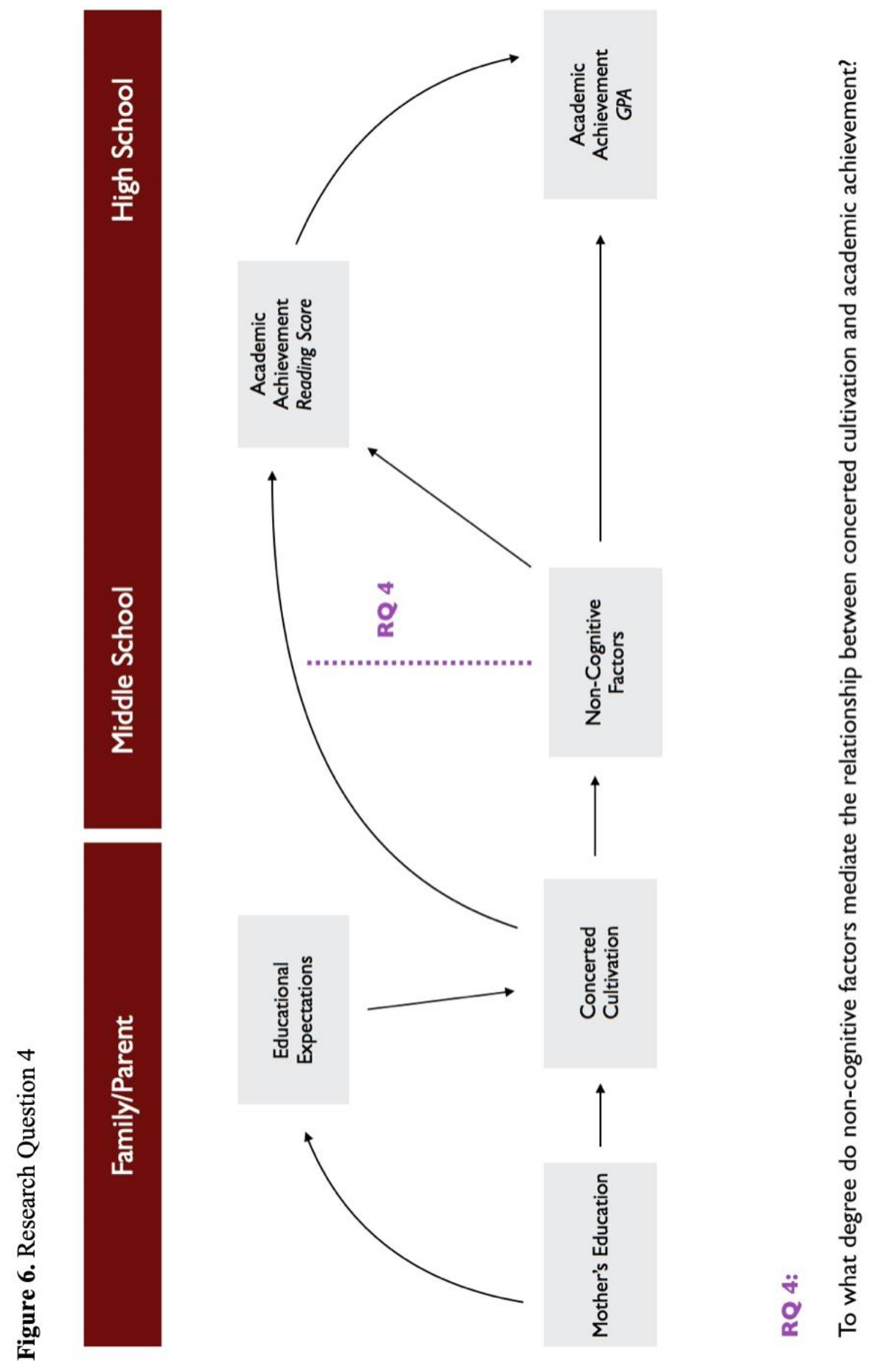




\section{References}

Alexander, Karl, Doris Entwisle, and Linda Olson. 2014. The Long Shadow: Family Background, Disadvantaged Urban Youth, and the Transition to Adulthood. New York, NY: Russell Sage Foundation.

Altintas, Edward. 2012. "Parents' Time with Children: Micro and Macro Perspectives." Unpublished doctoral dissertation, Nuffield College, University of Oxford.

Anyon, Jean. 2011. Marx and Education. New York, NY: Routledge.

Apple, Michael. 1979. Ideology and Curriculum. New York, NY: Routledge.

Bandura, Albert. 1977. Social Learning Theory. Englewood Cliffs, NJ: Prentice Hall.

Bandura, Albert. 1986. Social Foundations of Thought and Action: A Social Cognitive Theory. Englewood Cliffs, NJ: Prentice Hall.

Betts, Julian R. and Darlene Morell. 1999. “The Determinants of Undergraduate Grade Point Average.” Journal of Human Resources 34(2):268-93.

Blackwell, Lisa, Kali Trzesniewski, and Carol Dweck. 2007. "Implicit Theories of Intelligence Predict Achievement Across an Adolescent Transition: A Longitudinal Study and an Intervention." Child Development 78(1):246-263.

Bodivski, Katerina. 2014. “Adolescents' Emerging Habitus: The Role of Early Parental Expectations and Practices.” British Journal of Sociology of Education 35(3):389412.

Bodovski, Katerina and George Farkas. 2008. "“Concerted Cultivation' and Unequal Achievement in Elementary School.” Social Science Research 37(3):903-19.

Bollen, Kenneth A. 1989. Structural Equations with Latent Variables. New York: John Wiley and Sons. 
Borghans, Lex, Angela Duckworth, James Heckman, and Bas ter Weel. 2008. "The Economics and Psychology of Personality Traits." Journal of Human Resources 43(4):972-1059.

Bourdieu, Pierre, and Jean-Claude Passeron. 1977. Reproduction in Education, Culture, and Society. London: Sage.

Bourdieu, Pierre. 1977. Outline of a Theory of Practice. London: Cambridge University Press.

Bowles, Samuel and Herbert Gintis. 1976. Schooling in Capitalist America: Educational Reform and the Contradictions of Economic Life. Chicago, IL: Haymarket.

Bowles, Samuel, Herbert Gintis, and Melissa Osborne. 2001. "Incentive-Enhancing Preferences: Personality, Behavior, and Earnings." American Economic Review $155-158$.

Boyd, Don, Hamp Lankford, Susanna Loeb, Matthew Ronfeldt, and Jim Wyckoff. 2011. “The Effect of School Neighborhoods on Teachers' Career Decisions." Pp. 377396 in Whither Opportunity? Rising Inequality, Schools, and Children's Life Chances, edited by G. J. Duncan and R. J. Murnane. New York, NY: Russell Sage Foundation.

Calarco, Jessica. 2014. "Coached for the Classroom: Parents' Cultural Transmission and Children's Reproduction of Educational Inequalities.” American Sociological Review 79(5):1015-1037.

Calarco, Jessica. 2011. “'I Need Help!' Social Class and Children’s Help-Seeking in Elementary School.” American Sociological Review 76(6):862-82. 
Carolan, Brian and Sara Wasserman. 2015. 'Does Parenting Style Matter? Concerted Cultivation, Educational Expectations, and the Transmission of Educational Advantage.” Sociological Perspectives 58(2):168-186.

Carolan, Brian. 2015. "Unequal Academic Achievement in High School: The Mediating Roles of Concerted Cultivation and Close Friends.” British Journal of Sociology of Education 1:1034-1055.

Caspi, Avshalom. 2002. "Social Selection, Social Causation, and Developmental Pathways: Empirical Strategies for Better Understanding How Individuals and Environments are Linked Across the Life-Course.” Pp. 281-301 in Paths to Successful Development: Personality in the Life Course, edited by C. Avshalom and L. Pulkinnen,. Cambridge, UK: Cambridge University Press.

Center on Education Policy. 2012. "What Roles Do Parent Involvement, Family Background, and Culture Play in Student Motivation?” The George Washington University.

Cheadle, Jacob, and Paul Amato. 2011. “A Quantitative Assessment of Lareau's Qualitative Conclusions About Class, Race, and Parenting." Journal of Family Issues 32(6):679-708.

Cheadle, Jacob. 2008. “Educational Investment, Family Context, and Children's Math and Reading Growth from Kindergarten Through the Third Grade" Sociology of Education 81(1):1-31.

Coleman James.1966. Equality of Educational Opportunity. Washington, DC: US Government Print. 
Collins, Randall. 1979. The Credential Society: An Historical Sociology of Education and Stratification. New York, NY: Academic Press.

Collins, James. 2009. "Social Reproduction in Classrooms and Schools." Annual Review of Anthropology 38:33-48.

Conger, Rand D. and Katherine Conger. 2002. "Resilience in Midwestern Families: Selected Findings from the First Decade of a Prospective, Longitudinal Study." Journal of Marriage and Family, 64:361-373.

Conger, Katherine, Shannon Williams, Wendy Little, Katherine Masyn, and Barbara Shebloski. 2009. "Development of Mastery during Adolescence: The Role of Family Problem Solving.” Journal of Health Social Behavior, 50(1):99-114.

Conley, David. 2007. Toward a More Comprehensive Conception of College Readiness. Eugene, OR: Educational Policy Improvement Center.

Cunha, Flavio, and James Heckman. 2009. "The Economics and Psychology of Inequality and Human Development." Journal of the European Economic Association 7(2):320-364.

Darling-Hammond, Linda. 2012. “Two Futures of Educational Reform: What Strategies Will Improve Teaching and Learning." The Swiss Journal of Educational Research 34(1):21-38.

Davis-Kean, Pamela. 2005. "The Influence of Parent Education and Family Income on Child Achievement: The Indirect Role of Parental Expectations and the Home Environment." Journal of Family Psychology 19(2):294-304.

Duckworth, Angela, Eli Tsukayama, and Andrew Geier. 2010. Self-Controlled Children Stay Leaner in the Transition to Adolescence. Appetite 54(2):304-308. 
Duckworth, Angela and Martin Seligman. 2005. "Self-Discipline Outdoes IQ in Predicting Academic Performance of Adolescents.” Psychological Science 16(12):939-944.

Duncan, Greg and Richard Murnane. 2011. Whither Opportunity: Rising Inequality, Schools, and Children's Life Chances. New York, NY: Russell Sage.

Durik, Amanda M. and Jacquelynne S. Eccles. 2006. "Classroom Activities in Math and Reading in Early, Middle, and Late Elementary School." Journal of Classroom Interaction 41(1):33-41.

Durlak, Joseph, Roger Weissberg, Allison Dymnicki, Rebecca Taylor, and Kriston Schellinger. 2011. “The Impact of Enhancing Students' Social and Emotional Learning: A Meta-Analysis of School-Based Universal Interventions.” Child Development 82(1):405-432.

Dweck, Carol, Gregory Walton, and Geoffrey Cohen. 2011. Academic Tenacity: Mindsets and Skills that Promote Long-Term Learning. White paper prepared for the Gates Foundation. Seattle, WA.

Dweck, Carol. 2010. "Mindsets and Equitable Education.” Principal Leadership 10(5):26-29.

El Nokali, Nermeen, Heather Bachman, and Elizabeth Votruba-Drzal. 2010. Within-and Between-Child Parent Involvement and Academic and Social Skills in Elementary School. Child Development 81:988-1005.

Entwisle, Doris, Karl Alexander, and Lisa Olson. 2001.“Keep the Faucet Flowing: Summer Learning and Home Environment." American Educator 47:10-15. 
Farkas, George. 2003. "Cognitive Skills and Noncognitive Traits and Behaviors in Stratification Processes.” Annual Review of Sociology 29:541-62.

Farrington, Camille, Melissa Roderick, Elaine Allensworth, Jenny Nagaoka, Tasha Seneca Keyes, David W. Johnson, and Nicole O. Beechum. 2012. Teaching Adolescents to Become Learners: The Role of Noncognitive Factors in Shaping School Performance. Report prepared for the University of Chicago Consortium on School Research.

Gaddis, Michael. 2013. "The Influence of Habitus in the Relationship Between Cultural Capital and Academic Achievement." Social Science Research 42:1-13.

Gamoran, Adam, and Daniel A. Long. 2006. Equality of Educational Opportunity: A 40Year Retrospective (WCER Working Paper No. 2006-9). Madison, WI: University of Wisconsin-Madison.

Grolnick, Wendy, Rachel Friendly, and Valerie Bellas. 2009. Parenting and children's motivation at school. In K. R. Wentzel \& A. Wigfield (Eds.), Handbook of Motivation at School, 279- 300. New York \& London: Routledge.

Halpern, David. 2008. Social Capital. Cambridge: Polity Press.

Haertel, Edward. 2013. "Using Student Test Scores to Compare Teachers." in SCOPE Brown Bag Seminars, Graduate School of Education, Stanford University. Stanford, CA.

Hassrick, Elizabeth and Barbara Schneider. 2009. "Parent Surveillance in Schools: A Question of Social Class.” American Journal of Education 115:195-225. 
Hauser, Robert M., Shu-Ling Tsai, and William H. Sewell. 1983. “A Model of Stratification with Response Error in Social and Psychological Variables.” Sociology of Education 56(1):20-46.

Heckman, James. 2008. "Schools, Skills, and Synapses.” Economic Inquiry 46(3):289324.

Heckman, James, and Tim D. Kautz. 2012. "Hard Evidence on Soft Skills.” Labour Economics 19:451-64.

Heckman, James, Seong Moon, and Rodrigo Pinto. 2010. "The Rate of Return to the High Scope Perry Preschool Program.” Journal of Public Economics 94(1):11428.

Heckman, James, and Yona Rubinstein. 2001. "The Importance of Noncognitive Skills: Lessons from the GED Testing Program." American Economic Review 145-149. Hill, Heather C. 2016. "50 Years Ago, One Report Introduced Americans to the BlackWhite Achievement Gap. Here's What We've Learned Since." Chalkbeat.

Hill, Nancy, and Diane Tyson. 2009. "Parental Involvement in Middle School: A MetaAnalytic Assessment of the Strategies That Promote Achievement." Developmental Psychology 45(3):740-763.

Horn, Wade, and Thomas Packard. 1985. "Early Identification of Learning Problems: A Meta-Analysis.” Journal of Educational Psychology 77(5):597-607.

Hsin, Amy, and Yu Xie. 2016. "Life-Course Changes in the Mediation of Cognitive and Non-Cognitive Skills for Parental Effects on Children's Academic Achievement.” Social Science Research 63:150-165. 
Jennings, Jennifer L, David Deming, Christopher Jencks, Maya Lopuch, and Beth Schueler. 2015. "Do Differences in School Quality Matter More Than We Thought? Educational Opportunity in the 21 st Century." Sociology of Education 88(1): 56-82.

Kalil, Ariel, Rebecca Ryan, and Elise Chor. 2014. "Time Investments in Children across Family Structures." The Annals of the American Academy of Political and Social Science 654(1):150-168.

Kenny, David, Burcu Kaniskan, and Betsy McCoach. 2015. “The Performance of RMSEA in Models with Small Degrees of Freedom." Sociological Methods and Research 44(3):486-507.

Kornrich, Sabino, and Frank Furstenberg. 2013. "Investing in Children: Changes in Parental Spending on Children, 1972-2007.” Demography 50(1):1-23.

Lareau, Annette. 1987. "Social Class Differences in Family-School Relationships: The Importance of Cultural Capital.” The Sociology of Education 60(2):73-85.

Lareau, Annette. 2003. Unequal Childhoods: Class, Race, \& Family Life. Berkeley, CA: University of California Press.

Lareau, Annette. 2015. “Cultural Knowledge and Social Inequality.” American Sociological Review 80(1):1-27.

Lareau, Annette, and Elliot B. Weininger. 2003. "Cultural Capital in Educational Research: A Critical Assessment.” Theory and Society 32(5/6):567-606. Lee, Jihyun, and Lazar Stankov. 2016. "Non-Cognitive Influences on Academic Achievement." Pp. 153-169 in Non-Cognitive Skills and Factors in Educational 
Attainment, edited by M.S. Khine, and S. Areepattamannil. Boston, MA: Sense Publishers.

Lewis, Susan K., Catherine Ross, and John Mirowsky. 1999. "Establishing a Sense of Personal Control in the Transition to Adulthood." Social Forces 77:1573-1599. Li, Spencer. 2011. “Testing Mediation Using Multiple Regression and Structural Equation Modeling Analyses in Secondary Data.” Evaluation Review 35(3):240_ 268.

Liu, Airan. 2016. “Children's Non-Cognitive Skills and the Effects of Family SES on Academic Achievement.” Population Studies Center Research Reports 16(862):146.

Malecki, Christine, and Stephen Elliott. 2002. “Children's Social Behaviors as Predictors of Academic Achievement: A Longitudinal Analysis.” School Psychology Quarterly 17(1):1-23.

McCormick, Meghan, Elise Cappella, Erin E. O’Conner, and Sandee G. McClowry. "Parent Involvement, Emotional Support, and Behavior Problems: An Ecological Approach.” The Elementary School Journal, 114(2), 277-300.

McDonald, Roderick P. and Moon-Ho Ringo Ho. 2002. "Principles and Practice in Reporting Structural Equation Analyses.” Psychological Methods 7(1):64-82.

McLanahan, Sara. 2004. "Diverging Destinies: How Children Are Faring under the Second Demographic Transition.”Demography 41(4):607-627.

Myint, Swe Khine and Shaljan Areepattamannil. 2016. Non-Cognitive Skills and Factors in Educational Attainment. Boston, MA: Sense Publishers. 
Noble, Julie P. and Richard L. Sawyer. 2004. "Is High School GPA Better Than Admission Test Scores for Predicting Academic Success in College?" College \& University 79(4):17-22.

Oakes, Jeannie. 2015. "Research in the Ongoing Struggle for Educational Equity: An Agenda for the Future." Opening the Doors to Opportunity for All: Setting a Research Agenda for the Future. American Institute for Research.

Oyserman, Daphna, Kathy Terry, and Deborah Bybee. 2002. A Possible Selves Intervention to Enhance School Involvement. Journal of Adolescence 25:313-326.

Pearlin, Leonard I. and Carmi Schooler. 1978. "The Structure of Coping." Journal of Health and Social Behavior 19:2-21.

Peterson, James, and Nicholas Zill. 1986. "Marital Disruption, Parent-Child Relationships, and Behavior Problems in Children." Journal of Marriage and the Family 295-307.

Piketty, Thoma., \& Immanuel Saez. 2013. Downloadable Excel files with 2012 data updates to tables and figures in Piketty and Saez (2003). http://elsa.berkeley.edu/ saez/TabFig2012prel.xls

Planty, Michael, Robert Bozick, and Steven J. Ingels. 2006. Academic Pathways, Preparation, and Performance: A Descriptive Overview of the Transcripts from the High School Graduating Class of 2003-04. Washington, DC: U.S.

Department of Education, Institute of Education Sciences.

Polit, Denise. 1998. The Positive Behavior Scale. Saratoga Springs, NY: Humanalysis. 
Reardon, Sean, and Ximena Portilla. 2016. "Recent Trends in Income, Racial, and Ethnic School Readiness Gaps at Kindergarten Entry.” American Educational Research Association Open. 2(3).

Potter, Daniel and Josipa Roksa. 2013. “Accumulating Advantages over Time: Family Experiences and Social Class Inequality in Academic Achievement.” Social Science Research 42:1018-32.

Sewell, William H., Archibald O. Haller, and George W. Ohlendorf. 1970. "The Educational and Early Occupational Status Attainment Process: Replication and Revision.” American Sociological Review 35:1014-1027.

Sewell, William H. and Robert M. Hauser. 1975. Education, Occupation, and Earnings: Achievement in the Early Career. New York: Academic Press.

Shanahan, Michael, Shawn Bauldry, Brent Roberts, Ross Macmillan, and Rosemary Russo. 2014. "Personality and the Reproduction of Social Class." Social Forces 1-32.

Skinner, Ellen A. 1996. “A Guide to Constructs of Control.” Journal of Personality and Social Psychology 71:549-570.

Smith, Jane. 2006. "Parental Involvement in Education among Low-Income Families: A Case Study.” School Community Journal 16(1):43-56.

Stankov, Lazar, Suzanne Morony, and Yim Ping Lee. 2014. "Confidence: The Best NonCognitive Predictor of Academic Achievement?” Educational Psychology 34(1):9-28. 
Steele, Claude and Joshua Aronson. 1995. "Stereotype Threat and the Intellectual Test Performance of African-Americans.” Journal of Personality and Social Psychology 69:797-811.

Stephens, Nicole M., MarYam G. Hamedani, and Mesmin Destin. 2014. "Closing the Social Class Achievement Gap: A Difference-Education Intervention Improves First-Generation Students' Academic Performance and All Students' College Transition.” Psychological Science 25(4):943-53.

Sullivan, Alice. 2001. "Cultural Capital and Educational Attainment." Sociology of Education, 35(34):893-912.

Swartz, David. 1997. Culture and Power: The Sociology of Pierre Bourdieu. Chicago, IL: The University of Chicago Press.

Teo, Adrian, Elizabeth Carlson, Patrick J. Mathieu, Byron Egeland, and L. Alan Sroufe. 1996. “A Prospective Longitudinal Study of Psychosocial Predictors of Achievement." Journal of School Psychology 34:285-306.

Turner, Ralph H. 1960. "Sponsored and Contest Mobility and the School System." American Sociological Review 25(6):855-67.

Wang, Ming-te and Jacquelynne Eccles. 2012. "Social Support Matters: Longitudinal Effects of Social Support on Three Dimensions of School Engagement from Middle to High School." Child Development 83(3):877-895.

Walton, Gregory and Carol Dweck. 2009. "Solving Social Problems Like a Psychologist." Perspectives on Psychological Science 4:101-102. 
Wentzel, Kathryn. 1991. Social Competence at School: Relations Between Social Responsibility and Academic Achievement. Review of Educational Research $61: 1-24$

Wentzel, Kathryn. 1993. Does Being Good Make the Grade? Social Behavior and Academic Competence in Middle School.” Journal of Educational Psychology 85:357-364

Woodcock, Richard W., Kevin S. McGrew, and Nancy Mather. 2001. WoodcockJohnson Tests of Cognitive Abilities and Tests of Achievement. Rolling Meadows, IL: Riverside.

Yee, April. 2014. "Major Decisions: How Social Class Shapes Undergraduate Achievement." University of Pennsylvania, ProQuest, UMI Dissertations Publishing, 3623672.

Zwick, Rebecca and Jeffrey C. Sklar. 2005. 'Predicting College Grades and Degree Completion Using High School Grades and SAT Scores: The Role of Student Ethnicity and First Language.” American Educational Research Journal 42(3):439-64. 